أثر استخدام المحاكاة التفاعلية على تنميه التحصيل لاى تلاميذ الصف الساد الابتدائي في ماده العلوم إعداد

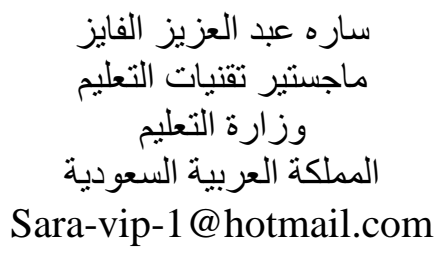

$$
\begin{aligned}
& \text { د. محمد شوقي شلتوت } \\
& \text { استاذ تكنولوجيا التعليم المساعد } \\
& \text { ومدير مركزي البحوث والتعلم الإلكتروني } \\
& \text { كليات الشرق العربي للدراسات العليا } \\
& \text { المملكة العربية السعودية } \\
& \text { M_shaltot@hotmail.com }
\end{aligned}
$$

\title{
مستخلص الدراسة
}

هدفت الدراسـة إلى معرفة أثر استخدام المحاكاة التفاعلية على تتميـه التحصيل لدى تلاميذ الصف السـادس الابتدائي في ماده العلوم حيث تم تحديد المشكلة بالسؤال التالي: مـا أثر استخدام المحاكاة التقاعلية على تتميه التحصيل لدى تلاميذ الصف السادس الابتدائي في ماده العلوم ماده العلوم وقد تقرع من هذا السؤال الاسئلة التالية: ا ـ مـا أثر اسـتخدام المحاكـاة التقاعليـة في تتميـه التحصـيل في مـاده العلـوم للصـف السـادس

$$
\text { الابتدائي؟ }
$$

r. هل هناك فروق دالة إحصائياً بين متوسطي درجات المجموعة التجربيية التي تعلمت باستخدام المحاكاة التفاعلية وبين المجموعة الضابطة التي تعلمت بالطريقة التقليدية؟ ولإجابة على هذه الاسئلة اتبع الباحثان المنهج شبه التجريبي حيث طبق على عينه عشوائية عبارة

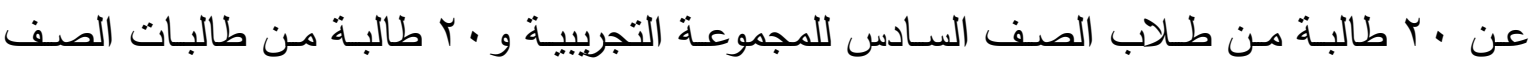

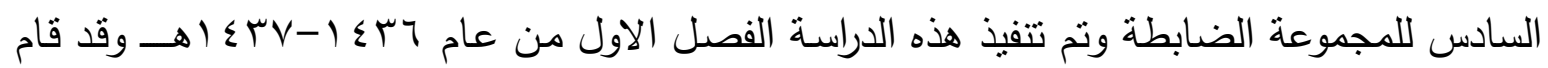
الباحثان بحساب معامل الصدق الثبات بإجراء اختبار تحصيلي على عينة استطلاعية حيث تكونت هذه العينـة مـن · r طالبـة مـن طالبـات الصف السـادس الابتدائي، وللتحقق مـن أهداف الدراسـة تم اخضاع المجموعتان التجريبية والضابطة لاختبار تحصيلي حيث اسفرت النتائج على: 


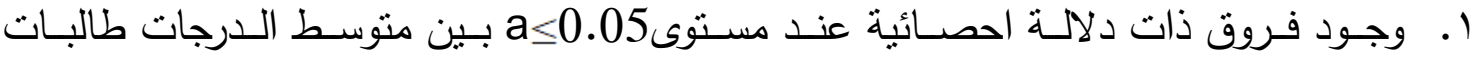

$$
\begin{aligned}
& \text { المجموعة التجريبية وطالبات المجموعة الضابطة في مستوى التذكر في الاختبار التحصيلي لصالح } \\
& \text { طالبات المجموعة التجريبية. }
\end{aligned}
$$

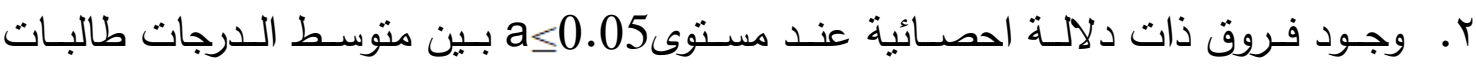

$$
\begin{aligned}
& \text { المجموعة التجريبية وطالبات المجموعة الضـابطة في مستوى الفهم في الاختبار التحصيلي لصالح } \\
& \text { طالبات المجموعة التجربيية. }
\end{aligned}
$$

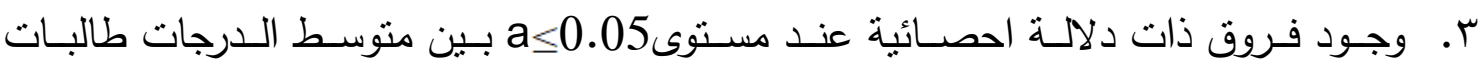

$$
\begin{aligned}
& \text { المجموعة التجريبية وطالبات المجموعة الضابطة في مستوى التطبيق في الاختبار التحصيلي لصالح } \\
& \text { طالبات المجموعة التجريبية. } \\
& \text { ـ. ـ وجـود فـروق ذات دلالـة احصـائية عنــ مسـتوى a بـين متوسـط الـدرجات طالبـات } \\
& \text { المجموعة التجريبية وطالبات المجموعة الضابطة في مستوى التحليل في الاختبار التحصيلي لصالح } \\
& \text { طالبات المجموعة التجريبية. } \\
& \text { 0. وجـود فـروق ذات دلالـة احصـائية عنــ مسـتوى 0.05 aـين متوسـط الـدرجات طالبـات } \\
& \text { المجموعة التجريبية وطالبات المجموعة الضابطة في مستوى التركيب في الاختبار التحصيلي لصالح } \\
& \text { طالبات المجموعة التجريبية. }
\end{aligned}
$$

\section{Abstract}

The effect of using interactive simulation on the achievement development for the sixthgrade students in science

The study aimed to investigate the effect of using interactive simulation on the achievement development for the sixth-grade students in science where the problem was identified with the following question: What is the effect of using interactive simulation on the achievement development for the sixth-grade students in science and from this question; the following questions are raised up:

1. What is the effect of using interactive simulation on the achievement development for the sixth-grade students in science?

2-Are there significant differences between the average scores of the experimental group which learned through using Interactive simulation and the control group that learned through the traditional way. 
To answer these questions researcher followed the semi experimental method where she applied on a random sample which is about 20 students from the sixth-grade students for the experimental group and 20 female students from the sixth grade to the control group and this study is performed in the first semester of 1436-1437 A.H, the researcher calculated through doing achievement test on an exploratory sample where this sample consisted of 20 female students from the sixth grade.

To investigate the objectives of the study, the two groups; the experimental and the control ones were subjected to an achievement test. Where results resulted on:

1-There are statistically significant differences at a 0.05 average scores between students of the experimental group and the control group students in remembering level in achievement test in favor of the students in the experimental group.

2- There are statistically significant differences at a 0.05 average scores between students of the experimental group and the control group students in the level of understanding in achievement test in favor of the students in the experimental group.

3- There are statistically significant differences at a 0.05 average scores

Etween students of the experimental group and the control group students in the application level in achievement test for the benefit of students in the experimental group.

4- There are statistically significant differences at a 0.05 average scores between students of the experimental group and the control group students in the level of analysis in the achievement test in favor of the students in the experimental group.

5- There are statistically significant differences at a 0.05 average scores between students of the experimental group and the control group students in composition level in achievement test in favor of the students in the experimental group.

1. The recommendations included the use of interactive simulation because of what is proven in its effectiveness in the development of scientific concepts and the achievement of the students.

2. Providing with all the necessary technology and infrastructure necessary to adopt the education system using interactive simulation. 3. The adoption of training programs necessary for female teachers which contribute in increasing their teaching skills using interactive simulation. 4. Training the female teachers on how to use modern technologies in education, especially interactive simulation because of what had been proven of its effectiveness in learning.

5. The adoption of using of interactive simulation by science teachers as one of effective means in teaching science.

6. Motivating students on learning by using interactive simulation. 


\section{المقدمسة}

أصبح استخدام التقنية في التعليم أمراً لابد منه لأن النقنية أصبحت متواجدة في كافّة مجالات حياتتـا ونتعامل معها بكل سـهوله وييسر ولقد أصبح استخدام التكنولوجيـا وعلى رأسـها الكمبيوتر ضرورياً في حياتتاً، وما نشاهده من تطور هائل وسريع في كفاءته يدعونا إلى تفعيله في مجال التعليم

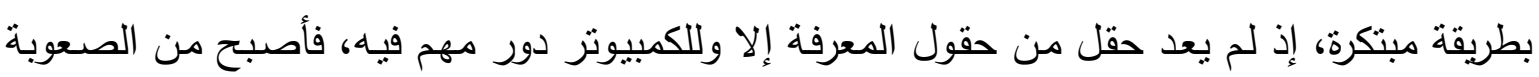

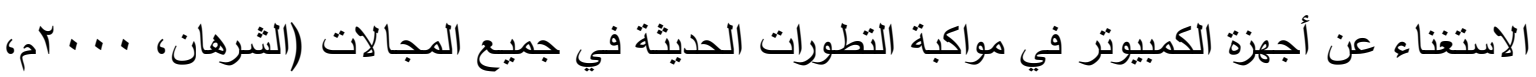
ص (1) (1) (1) (n)

وقد دعت العديد من المشاريع إلى استخدام الثنّنية في التعليم منها (مشروع العلم والثتنية والمجتمع) (ومشروع العلم لكل الأمريكين) حيث وجد أن • 9\% من معلمي العلوم يستخدمون الكتاب المدرسي لما فا

$$
\text { يمثل نسبة • 9\% من المنهج الدراسي (الديك, • ( • ( ). }
$$

ومن مجالات استخدام التقنية في التعليم برامج الدحاكاة الإلكترونية الحديثة مثل البرامج ثلاثية

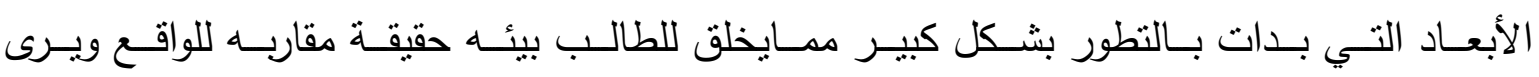

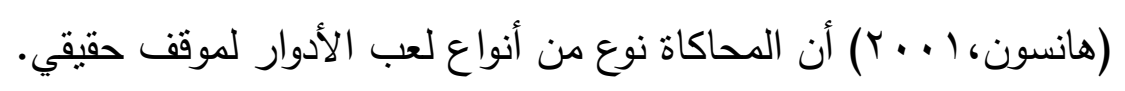

ولقد دللت العديد من الدراسـات على اهيـه استخدام البرامج ثلاثيـة الأبعاد في التدريس دراسـة

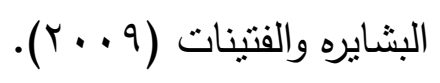

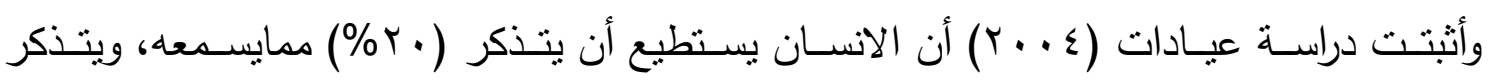

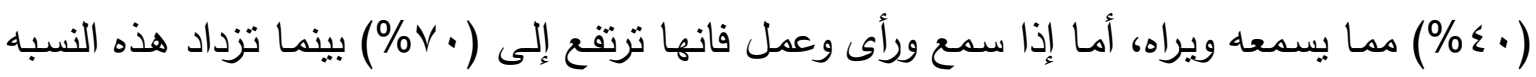
في حاله تفاعل الانسان مع مايتعلمه. (اليحى, ؟ ـ بـ). وتعد المرحلة الإبتدائية الركيزه الأساسية لبناء المفاهيم والمعارف وأي تعثر فيها يؤثر بصورة كبيرة في المراحل التي تليها لذلك حرص مطورو المناهج إلى تطوير المناهج في هذه المرحلة بالذات وقد أنتارت العتيق في دراستها أن مناهج العلوم تركز على تقديم المعارف المجرده والتي تقدم كمجموعة

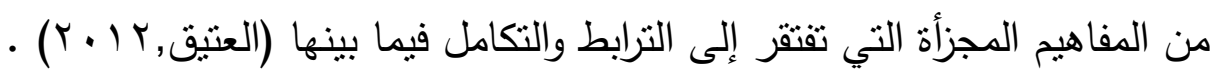

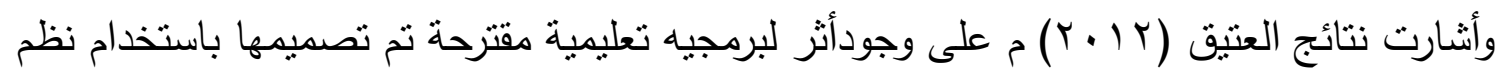
الوسائط المتعده في تحصيل تلاميذ الصف السادس الإبندائي لوحدة دراسية في العلوم. 


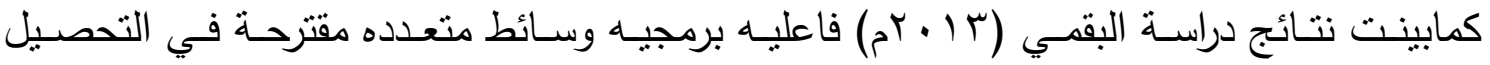
الدراسي وبقاء أثز التعلم لطالبات الصف الاول المتوسط في وحدة دراسية من مقرر العلوم. لذلك تزيد البيئات الافتراضيه ثلاثية الأبعاد من دافع الطالب الذي هو عاملا قويا بساهم في التعلم ويلاحظ ذلك عندما يكون الوقت الذي يقضبه الأفراد بين ألعاب الكمبيوتز وألعاب الفيديو والألعاب التفاعلية يستهلك من ساعه إلى ^ ساعات يومياً فالدافع يبدو للوصول للبيئات ثلاثية الأبعاد (اليحى، $\cdot(r \cdot) \leq$ كما وفرت بعض المواقع منصّات ثلاثية الأبعاد تمكن الطالب من التفاعل المباشر في بيئه محاكاة ثلاثية الأبعاد ومن هذه المنصّات zspace وهي شركه رائده على مستوى العالم في نقديم الحلول التي تمكن من التفاعل الطبيعي في الحاسب مـع المجسمات والاثكال ثناثية الأبعاد في بيئه هولوجرافيه افتراضيه. (2015،zspace) ويتضـح مماسبق أن برامج المحاكاة تقرب الواقع للمتعلم عن طريق نقله إلى حجرات الدراسة في صوره نماذج، مما يثير رغبه المتعلم في التعلم ويتيح له فرصده التخيل عن طريق العرض البصري المثير والمشوق ومن خلال مماسه المتعلم للنشاط التخيلي يتحرر التلميذ من الجمود العقلي ممايدفعه

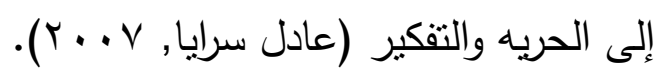

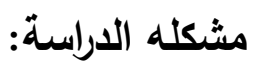

ظهرت المشكلة من خلال عمل أحد الباحثين كمعلمة لمادة العلوم بدات تظهر مشكلة الدراسة حيث وجدت صعوبه في ايصال مفهوم بعض التفاصيل الدقيقه من اجزاء جسم الكائن الحي للطالبات في المرحلة الإبتدائية، وللتأكد من أن هناك مشكله حقيقة وتحتاج إلى دراسة وبحث قام الباحثان باجراء دراسة استطلاعيه على • ( معلمات لدراسـة واقع معلمي العلوم في تدريس ماده العلوم والصعوبات التي تواجههم في ايصـال المفـاهيم الدقيقهـ لاجزاء جسم الكائن الحسي حيث أظهرت هذه الدراسـة الاسنطلاعية مايلي. - أن الاغلبيه العظمى من المعلمات اقتصرو على الكتاب وعروض الباوربوينت من الكتاب

- أن الاقليه من المعلمين استفادوا من بعض برامج اليوتيوب مثل الافلام الوثائقيه. -جهل المعلمين وعدم استفادتهم من برامج الدحاكاة التفاعلية الموجوده في الأجزة المحمولة. 
-وقد أكدت أيضاً العديد من الدراسات على ضرورة تبني طرق واستراتيجيات حديثة في التعليم منها مؤتمر التربيه التكنولوجيه وتكنولوجيا التعليم (جامعة الأقصى، ـ 1 ـ ب)، ومؤتمر من التعليم إلى

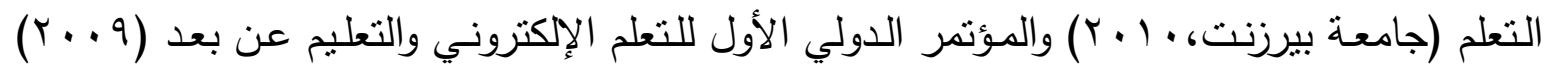
والتي أكدت على ضرورة تبني طرق واستراتيجيات حديثة في التعليم، وتركزت مشكلة الدراسـة في

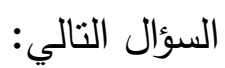

مـا أثر استخدام المحاكساة التفاعلية في تنميسه التحصيل في مـاده العلوم للصف السـادس

الإبتدائي؟

وتفرع منها سؤال فرعي وهو : هل هناك فروق دالة إحصائياً بين منوسطي درجات المجموعة

التجريبية التي تعلمت باستخدام المحاكاة التفاعلية وبين المجموعة الضـابطة التي تعلمت بالطريقة

الثقلبدية؟

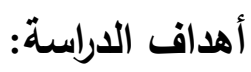

$$
\text { يسعى هذا البحث إلى: }
$$

• التعرف على أثز استخدام المحاكاة التفاعلية في تتميه التحصيل في ماده العلوم للصف السادس

$$
\text { الإبندائي. }
$$

التعرف على ما إذا كان هناك فروق دالة إحصائياً بين منوسطي درجات المجموعة التجريبية

التي تعلمت بالمحاكاة التفاعلية وبين المجموعة الضابطة التي تعلىت بالطريقة التقليدية.

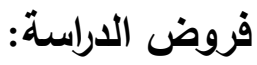

• لأسلوب التعلم بمساعدة المحاكاة التفاعلية أثر إيجابي في تتميه التحصيل لطالبات الصف رف

$$
\text { السادس بماده العلوم }
$$

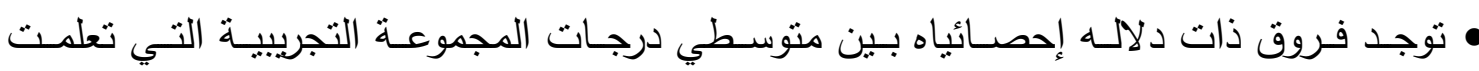
بالمحاكاة التفاعلية وبين المجموعة الضابطة التي تعلمت بالطريقة التقليدية. 
- - المساعدة في الحد من النقص الحاصل في التقنيات التعليمية المعنيةعلى تدريس العلوم عدا أنه في حالة الكثف عن وجود أثر إيجابي لاستخدام هذا البرنامج على تحصيل الطالبات، يمكن تعميم نتائجه للإفادة منه تدريس العلوم ولتقديم طريقة تعليمية متميزة. - - التأكيد على أهمية استخدام التكنولوجيا الحديثة، وكيفية الاستفادة منها في تدربس العلوم - قد ينتج عن الدراسة الحالية توضيح باهيه المحاكاة التفاعلية لتدريس العلوم لما لها من فائده في محاكاة الواقع الفعلي، وذلك لزيادة التحصيل العلمي لطالبات الصف السادس الإبتدائي. حدود البحث: الحدود الموضوعيه: اقتصر هذا البحث على تحديد أثر استخدام المحاكاة التفاعلية في تتميه التحصيل في ماده العلوم للصف السادس الإبتدائي، وتم استخدام برنامج HUMN وهي منصة تعليمية ثلاثية الأبعاد، وتم التطبيق في درس اجهزة الجسم لمادة العلوم للصف السادس الابتدائي المتغير المستقل: أثز استخدام المحاكاة التفاعلية المتغير التابع: تتمية التحصيل في مادة العلوم الحدود المكاتيه: اقتصر هذا البحث على تطبيقه بمدرسه حكوميه الب شمال الرياض.

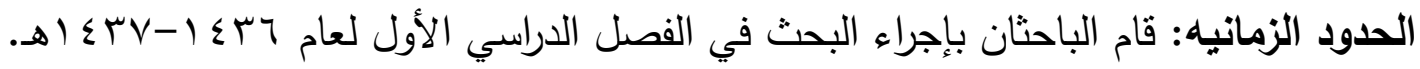
مصطات الاراسة: التعريف الاجرائي المحاكاة التفاعلية : يعرفه الباحثان المحاكاة التفاعلية بأنها برامج حاسوبيه صمدت في بيئه ثناثيـة الأبعاد بتفاعل فيها الطالب مـع الصـور والاشكال بشكل مباشـرعن طريـق محاكاة بيئه افتراضيه ثثلاثية الأبعاد. أدبيات البحث والدراسات السابقة:

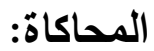

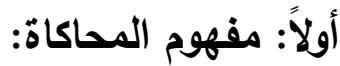

هناك عدة تعريفات لمفهوم المحاكاة فقد عرفها الديك ( • ( • ( المحاكاة هي عمليه تقليد محكم لظاهرة اولسلوك أو لموقف أو لحاله أو لمشكلة أو لنظام حقيقي ويتم تقديم ذلك عن طريق النمذجهـ المحاكيـة بشكل يتيح لكل مشـارك فيها دورا معينـا بستهدف تدربيـه على حل المشكلات واكتشـاب المهارات وأنها تستخدم للتخلب على عاملي الزمان والمكان وتعطي نتائج مشابهه للواقع. 


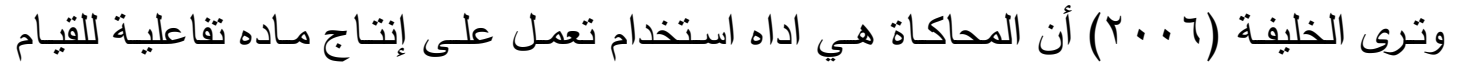
بنشاط محدد، أو غير تفاعلية لسرد أو استعراض وظيفة معينه. ويرى زيتون (ع . . r) أن المواقف التعليمية لمحاكاة نموذج لنظام أو مشكلة موجودة في الواقع حيث يبرمج هذا الواقع داخل الكمبيوتز على شكل معادلات تمثل بدقه العلاقات المتبادله بين مكوناته المختلفه.

وتعرفها رباب ( • ( • أنها مجموعة مواقف تعليمية متضـنه نظام موجود في الواقع يمثل بواسطة الكمبيوتز وتضم هذه المواقف التعليمية لتحقيق الادراك البصري للمفاهيم البصرية. ثانياً: العلاقة بين المحاكاة والنمذجة: ويرى مرعي والحيله (· ( • أن أنموذج هو محاكاة مجسمه لثـئ ما وقد يكون مطابقا للشئ المقلد أو بسيطا مجردا من التفاصيل غير الضـروريه وقد يكون على شكل مقطع أو يمثل الشكل الخارجي فقط. ويرى عزمي (0 1 • أن المحاكاة تختلف عن النمذجه في عده سمات فهي لاتحتمل صفة الاختصار أو التكوبد بقدر ماتحمل من مشابهه وتمثيل تصويري تفصبلي واهم مايميز المحاكاة عن

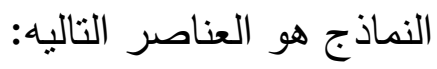
التفاعليـة: مـايميز المحاكاة عن النمذجهـه هي تفاعليـة المحاكاة بحيـث تعطي المحاكاة دورهـا الديناميكي. القدرة التشـابهية: للنمـاذج قدرة على مضـاهاه الاصـل والقدرة على أن تكـون نسـخه منهـا مـع امكانية أن يكون أكبر أو أصغر حجما ولكن ليس النتشابهه التام بالضرورة لوجود المحاكاة التكرار : المحاكاة خاصة الرقمية منها تحمل قدرات التكرار أي اننا يمكنا أن نبني محاكاة لمنتج ما وفي نفس الوقت إنتاج عدد من هذه المحاكاة معا. مكونات برامج المحاكاة الكمبيوتريه: تتكون برامج المحاكات من ثلاث عناصر يمر بها المتعلم ويتفاعل معها حتى يصدر استجاباته

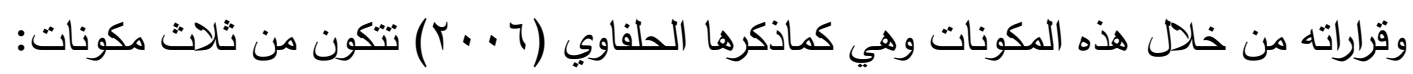
المقدمـة: يعرض في المقدمـة الأهداف الخاصـة بالمحاكاة وسـيناريو وأدوار المتعلمين والمعلم بحيث يتعرف من خلالها كل متعلم على دوره الذي يقوم بـا 
التفاعل: وفيه يتفاعل المتعلمون عبر الكمبيوتز من خلال الموقف التعليمي وتتثيل الأدوار عبر

الكمبيوتز

استخلاص المعلومات: يظهر المتعلمون النتائج من خلال مامرو به من تفاعل عبر الكمبيوتر

حيث ينواصلون إلى الاستجابات المطلوبة.

ثالثاً: خصائص المحاكاة التعليمية:

تفوقت المحاكاة في التعليم عن بقية طرق وأساليب التعليم وذلك لخصائصها الفريدة التي أكد عليها كل من " نافارو وفان ديرهوك, ع . . ץ" والتي يمكن ذكرها كما يلي: تسمح المحاكاة للمتعلمين باكتساب الخبرات التي قد تكلفهم مبالغ طائلة عند كل محاولة للتجريب. • تحمي المحاكاة المتعلم من المواد والمواقف الخطرة التي يمكن أن تتتج من التجربة الحقيقية، حيث يمكن للمتعلم تكرار التجارب وبشتى الطرق المتتوعة. تثميز المحاكاة بالسهولة حيث نسمح للمعلم بتجريب مختلف الأنماط مـع المتعلم حتى يستطيع مواجنتها بمفرده فيما بعد.

• يمكن أن تتم العملية في المحاكاة بأسرع منها في الواقع، كما يمكن أن تستغرق وقتاً أكثر مما هي بهرد عليه في الحقيقة. ويرى قنديل (999 (م) وإسماعيل (1 (1) أن من مميزات المحاكاة في بيئة التعلم التفاعلية التي قلما تتوفر في المواد التعليمية الاخرى مايلي الثواب والعقاب الفوري في أثناء التعليم. •تتدرج مع قرارات المتعلم من السهل إلى الصعب فالأصعب. توفر درجات عالية من الانتباه والتفاعل بين الاطفال ممايجعل المادة العملية ممتعه. • تحتوي غالبا على عدة عناصر تطفئ للاثارة والنتشويق على المادة العلمية مدتعه. تهتم بالتغذيـة الراجعه والتحفيز المعنوي تيسير فهم المعلومات المجرده من خـلال تمثيل برامج الكمبيوتر لها.

• تيسير فهم المعلومات المجرده من خلال تمثيل برامج الكمبيوتر لها. • تكسب مهارات المشكلات واستخدام قدرات تفكيرية متتوعة. تشاعد على استكثاف المعلومات بطريقة تفاعلية ديناميكية. رابعاً: المبررات لاستخدام المحاكاة: 
ذكر ابو السعود (•rع () أن هناك العديد من المبررات التي تستخدم من اجلها المحاكاة في مجال التعليم ومنها ما يلي:

1-التكلفه: تستخدم المحاكاة حينما تكون التجارب المعملية مكلفه، اوعند استحالة تتفيذ الانشطة الحقيقيه في غرفة الدراسة.

ب-الخطورة: تستخدم المحاكاة في التجارب المعملية الخطره مثنل المفاعلات النوويـه والذربـه

$$
\text { وتجارب الاشعاع. }
$$

ب-اختزال الوقت: تستخدم المحاكاة حينما يتطلب الامر دراسة النموذج الحقيقي إلى وقت طويل منل نموذج لنمو النباتات أو نموذج الجينات البشري هاو نموذج لاحداث وقعت في الماضي. ع-الصغر : منل نموذج لدراسة الذرة أو البكتربا.

ه-التدريب: حيث تسمح المحاكاة من خلاله للمتدربين التعامل مع مواقف مبسطه على الثاشـه تناظر ما يحدث في دنيا الواقع كدراسة مناسك الحج وتدريب الطيارين. ד-التكرار : حيث يمكن عرض وتكرار المعلومات والبيانات والمحتوى التعليمي منى شاء ذلك. V-المرور بخبره يستحيل الحصول عليها في الحياة العاديه. أنماط المحاكاة التعليمية: تأخذ المحاكاة عدة أشكال منها: تمثيل الأدوار أو (النمذجـة الإنسانية)، وتتصف بالتفاعل غير المحدد بين الأفراد من خـلال تقمص شخصيات أخرى في مواقف حياتيه. • نموذج مطابقة الواقع (النمذجة العلمية): تسمى الأجهزة التي تكون على شكل نموذج مطابق للأجهزة الحقيقيـة، ومصـغره حسب نسبة معينـه، تسـى النمذجـه المحاكية للواقع، مثل نمـاذج التدريب على الطيـران، ولكن بوجود غرفـه بكامل أدوات التحكم الموجودة في غرفه التحكم بالطائرة.

المسابقة (المباراة / اللعبة): وهي نشاط تتافسي منظم، بين أثثين أو أكثر من المتعلمين ضمن قواعد متعبـه، وأهداف محدده مسبقاً، وتتتهي عادة بفائز ومهزوم، بسبب اختلاف المهارات، وبالرغم من وجود عنصر المحاكاة والمسابقة والتدرب بشكل منفرد، إلا أن اللعبون يمكنهم أن 
يتــاخلوا ويتفــاعلوا معـاً ليشـكلوا نموذجـاً متـداخلاً وشــاملاً لخصــائص الأنشـطة. (فرانــك

$$
\begin{aligned}
& \text { كليش، ... } \\
& \text { المحاكاة في تدريس العلوم: }
\end{aligned}
$$

نادى المتخصصون في التربية بالابتعاد عن تلقين العلوم، وتقديمها بطريقة متغيرة ومتجدده مع عدم الاقتصار على طريقة واحدة مما أدى إلى استخدام الحاسوب في التدريس لجميع المراحل التعليمية. حيث أن ما أنتجته المؤسسات من برمجيات تعليمية يستفاد منها في المخابر العلمية، وفي الصفوف الصف

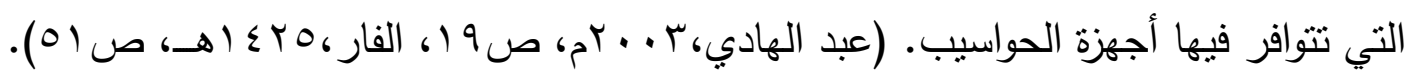
وتعتبر مواد العلوم من المجالات الخصبة لنطبيق برامج المحاكاة الحاسوبية عليها فبواسطة المحاكاة يمكن تمثيل الكثير مـن الظواهر العلميـة. حيث يتميز تدريس العلوم باستخدام المحاكاة بمجموعة من المميزات: • نساعد الطلاب على فهم المفاهيم العلمية بشكل صحيح والتي ينطلب فهمها إلى اظهار الجانب الحركي في الموضوعات أو الظواهر التي تنظمنها. • تحسين مسنويات مهارات التفكير المختلفة، كمهارات عمليات العلم ومهارات حل المشكلات ومارات التفكير الناقد. • تفهم أبعاد الظواهر الطبيعية التي لايمكن مشاهدتها في حياة الطلاب، وكأنهم يعيشون وسط هذه

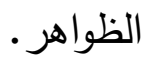
عرض الموضوعات العلمية على الطلاب بشكل يتطلب منهم التفاعل والمناقنـة والعمل في مجموعات وتتفيذ أفكارهم المتادولة، وطرح الأسئلة حولها، وبالتالي يمكنه التصدي للنتائج

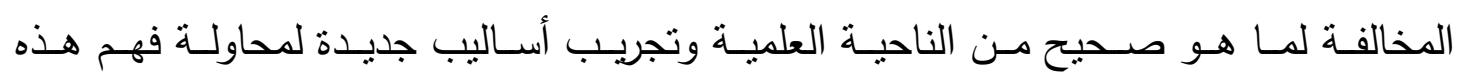

$$
\text { الموضوعات. (ال حمزة، rا • Y، זr). }
$$

ومن الممكن استخدام المحاكاة الحاسوبيه حين تواجه معلمة العلوم صعوبة في تمكين إجراء التجارب بالمختبرات أو إجراء عرض واقعي لها، لصعوبات مالية أوإدارية أو فنية أو خشية الحوادث والأخطار الناجمة عن التجارب الواقعية.كمايمكن للحاسوب إجراء القياسات المستمرة الواقعية،وتسجيل

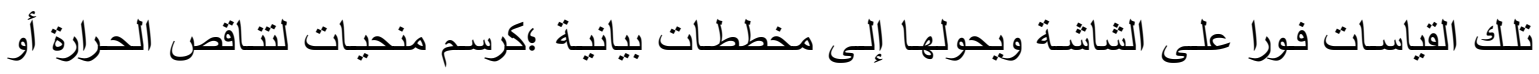

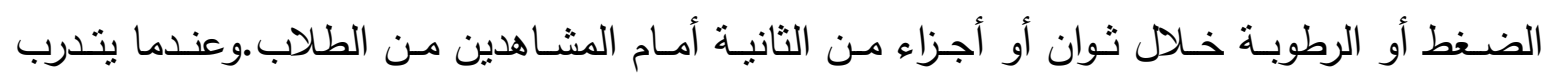


الطـلاب على اسـتخدام الحاسـوب بكونـهـ أداة مخبريـة،يتعلمون أشـياء كثيـرة عـن تشـغيلة وأنظمتهـ وصيانته،ويستفيدون من هذا التعلم غير المباشر في تتمية الثقافة الحاسوبية والمعلوماتية،والتي هي مطلب يتطلبه عصر المعلومات،مكمل لمايدرسونه من خلال مقررات علوم الحاسوب بمدارس التعليم العام والجامعي (الفار 0.0 ع أهـص (0). الاراسات السابقة:

\section{دراسة أبو ماضي (r \& \& I):}

هدفت الدراسـة إلى الكثـف عن أثنر المحاكـاة الحاسـوبيه على اكتشـاب المفـاهيم والمهارات الكهربيه بالتكنولوجيا لدى طلبه الصف التاسع الأساسـي بغزه واسفرت نتائجها علي انه توجد فروق ذات دلاله احصـائيه عند مستوى (0,05) بين متوسط درجات طالبـات الجموعـه التجريبية ومتوسط درجات طالبات المجموعـه الضـابطة في الاختبـار المعرفي للمفاهيم والمهارات الكهربيه وفي بطاقه الملاحظه للمهارات الكهربيه وكذلك توجد فروق ذات علاقة ارتباطيه موجبه الأشاره ومتوسطه القيمه (0,53) بين درجات طالبات المجموعتين في الاختبار المعرفي لمفاهيم والمهارات الكهربيه وبطاقه الملاحظه للمهارات الكهربيه

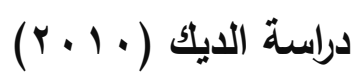

هدفت الدراسة إلى تقصي أثز المحاكاة بالحاسوب على التحصيل الاتي والمؤجل لطلبه الصف الحـادي عشـر العلمي واتجاهـاتهم نحو تعلم وحدة الميكانيكاومعلمها في المـارس الحكوميـه التابعـه لمديريـة جنوب نـابلس وقد تكونت العينـه من VII Vالب وطالبـه موزعين لى اربع شعب في اربع مدارس مختلفه مدرستان للاولاد ومدرستان للبنات وتوصلت الدراسـة إلى أنـه نوجد فروق ذات دلاله احصائيه بين متوسطات تحصيل طلبة الصف الحادي عشر العلمي ومتوسطات اتجاهاتهم نحو تعلم الميكانيكاونحو معلمها الذين تعلموها بالحاسوب تعزي للجنس وعدم وجود بين متوسطات تحصبل طلبة الصف الحادي عشر العلمي في الميكانيكا ومتوسطات اتجاهـاتهم نحو تعلم الميكانيكاونحو معلمها تعزي إلى التفاعل والجنس وعدم وجود فروق بين منوسطات تحصيل طلبـة الصف الحادي عشر العلمي في اختبار المعرفه البعدي الاني ومتوسطات تحصيلهم في اختبار المعرفي البعدي المؤجل.

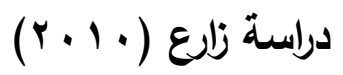


هـفت الدراسـة إلى فاعليـة برنـامج مقترح قـائم على المحاكـاة الإلكترونيـة لتدريس الدراسـات الاجتماعية لتدريس الدراسات الاجتماعيه في تتمية التحصيل والقدره المكانيه والاتجاه نحو الماده لدى تلاميذ المرحلة الإعداديـة، وأظهرت النتائج فاعلية البرنامج المقترح في تدريس موضوعات الجغرافيا بمقرر الدراسات الاجتماعيه لدى التلاميذ.

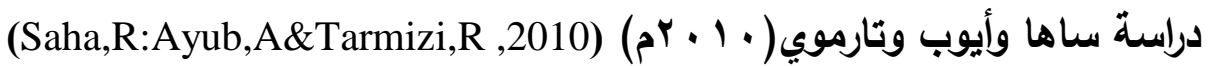
هدفت الدراسة إلى الكثف عن فاعلية استخدام برمجية للمحاكاة الثلاثية الأبعاد في تتمية التحصيل الدراسي للطلاب في الرياضيات ودورها في تعلم الهندسة التحليلية، وكانت النتائج بمستويات عاليه في التحصيل الدراسي للمجموعـه التجريبية في الرياضيات وخاصسه الهندسه مقارنـه للمجموعه الضـابطة،وقد أكدت النتائج على فاعلية برمجية المحاكاة المقترحة في الارتقاء بالجوانب التاليه لتعليم الرياضيات وهي تتميه التحصيل اللدراسي ودعم القدرات البصريه وتتمية قدرات الطلاب على دراسة الاشكال والمساحات الهندسيه.

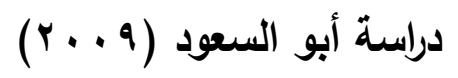

هدفت الدراسة إلى التعرف على فعالية برنامج تقني قائم على اسلوب المحاكاة في تنمية بعض مهارات مساوراء المعرفه في منهاج العلوم لدى طلبـة الصف التاسـع الأساسـي بغزة، وكثـفت نتائج الدراسـة عـن وجـود فـروق ذات دلالـه احصـائيه بـين متوسـطات درجـات طلبـة المجموعـه التجريبيـة والضابطة في القياس البعدي لمهارات ماوراء المعرفه لصالح طلبة المجموعه التجريبية كما توجد فروق ذات دلالـه احصـائيه بين منتوسطات درجـات طالبـات المجموعتين التجريبيـة والضـابطة في القياس البعدي لمهارات ماوراء المعرفه لصالح طالبات المجموعه التجريبية

\section{دراسة كوثر "ماكام" (Mcadam,2010)}

الهدف مـن الدراسـة هو الوقوف عى فاعليـة استخدام برمجيـات المحاكـاة التفاعليـة في تتميـة مستويات تحصيل الطلاب وقدرتهم على فهم موضوع نظم الديناميكا الحراربه في ماده العلوم، وكانت النتائج النهائيه للدراسة فاعلية استخدام برمجيات المحاكاة التفاعلية في تتمية التحصيل المعرفي وقدرة الطلاب على الفهم والاستيعاب للموضوع الدراسي المطلوب في ماده العلوم.

دراسة بيل ودروندال (Bell\&Trundle,2008) 
تتاولت الدراسـة إلى فاعليـة المحاكاة الحاسـوبيه من خـلال مقارنـة الفهم للمفـاهيم القمريـة لدى معلمي رياض الاطفال قبل الخدمها وذلك قبل وبعد التدريس تقصيا باستخدام برنـامج "الفناء الخلفي الملئ بالنجوم ليلا " stary night Backyard"، وأظهرت النتائج بعد المقارنـه أنه لم يكن قبل التدريس لدى احد من المشاركين تصور عن أسباب اطوار القمر ولا مقدره على رسم شكله أو تطوره في حين أنه بعد التدريس باستخدام تقنية المحاكاة أصبح معظم المشـاركين (Y^\%) لديهم تصور علمي عن اسباب مراحل تطور القـر كمـا أن (،^\%) منهم أصبحو قادرين على رسم اشكال القـر ومراحل تطوره. التعليق على الدراسات: يتضـح مما سبق أن الدراسـات والبحوث السـابقه تتاولت استخدام المحاكاة الحاسوبية في تعليم العلوم في موضـوعات مختلفة ولدى فئات متباينه ويمكن تلخيص السـمات العامـة لها على النحو التالى تتوعت المراحل التي تطرقت اليها الدراسـات السابقة حيث شملت مرحلة الثانويه كما في دراسـة

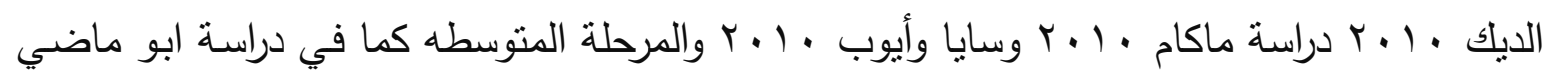

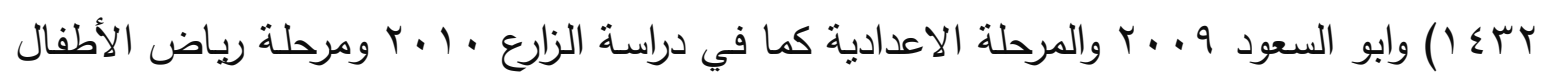

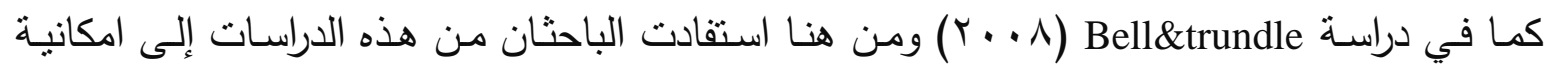
تطبيق المحاكاة في المرحلة الإبتدائية، وتتوعت الدراسات السابقة من حيث تجريب المحاكاة الحاسوبية في محالات تعليم العلوم المختلفة فتوجد في مجال الميكانيكا كما في دراسة الديك ( • • ب) وفي مجال

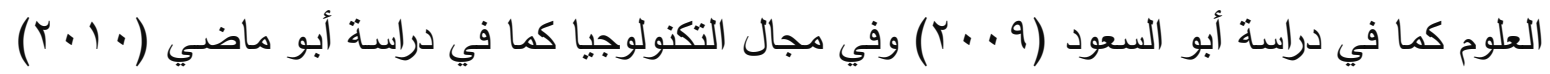
وفي مجال الدراسات الاجتماعية كما في دراسة زارع (· ( • (ب) وفي مجال الرياضيات كما في دراسـة

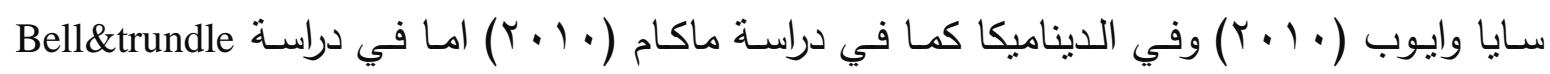

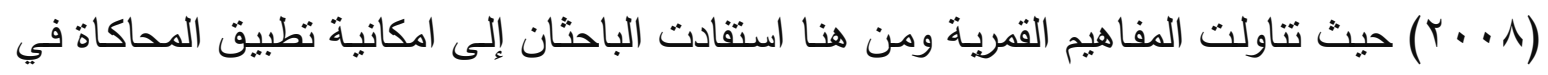
مجال العلوم، واهتمت دراسات بالمحاكاة مع متغيرات تابعه أخرى مثل التحصيل الاني والمؤجل وتتمية التحصيل والقدره المكانيه والاتجـاه نحو المساده واتجاهاتهم نحو تعلم وحدة الميكانيكا ومعلمها دراسـة

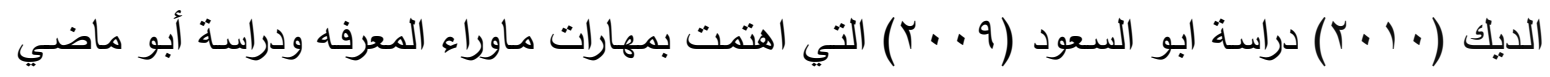
( • ( ب ) التي اهتمت بالمفاهيم والمهارات الكهربيه ومن هنا استفادت الباحثنان إلى امكانية استخدام 
المتغير التابع تتمية التحصيل، واختلفت الدراسـات السـابقه بـالادوات التي استخدنها حيث استخدم

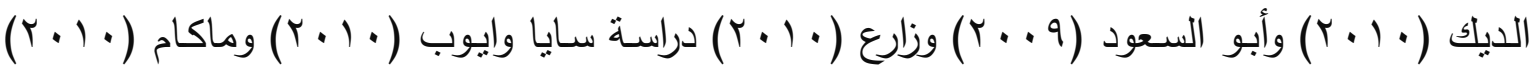

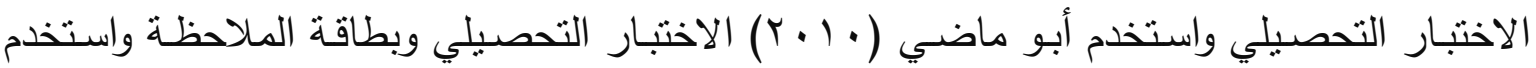

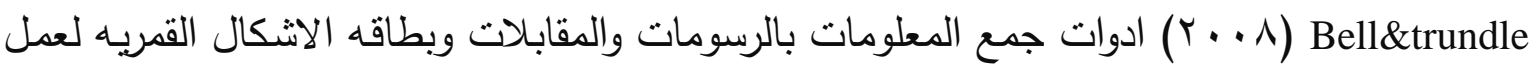
ملف لكل مشارك ومن هنا استفادت الباحثان من امكانية تطبيق الاختبار التحصيلي كاداة في الدراسة.

\section{منهجية الاراسة واجراعتها}

أولاً: منهج الاراسة:

اعتمد الباحثان على المنهج شبه التجريبي ويقوم هذا المنهج على أساس العلاقة السببية بين متغيرين أحدهما المتغير المستقل المتمثل في المحاكاة التفاعلية، والآخر المتغير التابع المتمثل في تتميه التحصيل في ماده العلوم للصف السادس الإبتدائي. وقد استخدم الباحثان التصميم شبه التجرييـي ذو المجموعتين التجريبيـة والضـابطة حيث تم اختيار مجموعتين من الطالبات تمثل إحدى المجموعتين المجموعة التجريبية والتي درست باستخدام المحاكاة التفاعلية بينما درست المجموعة الضـابطة باستخدام الطريقة التقليدية (كما موضح بالثنكل

\section{شكل (ץ): التصميم شبه التجريبي للبحث}

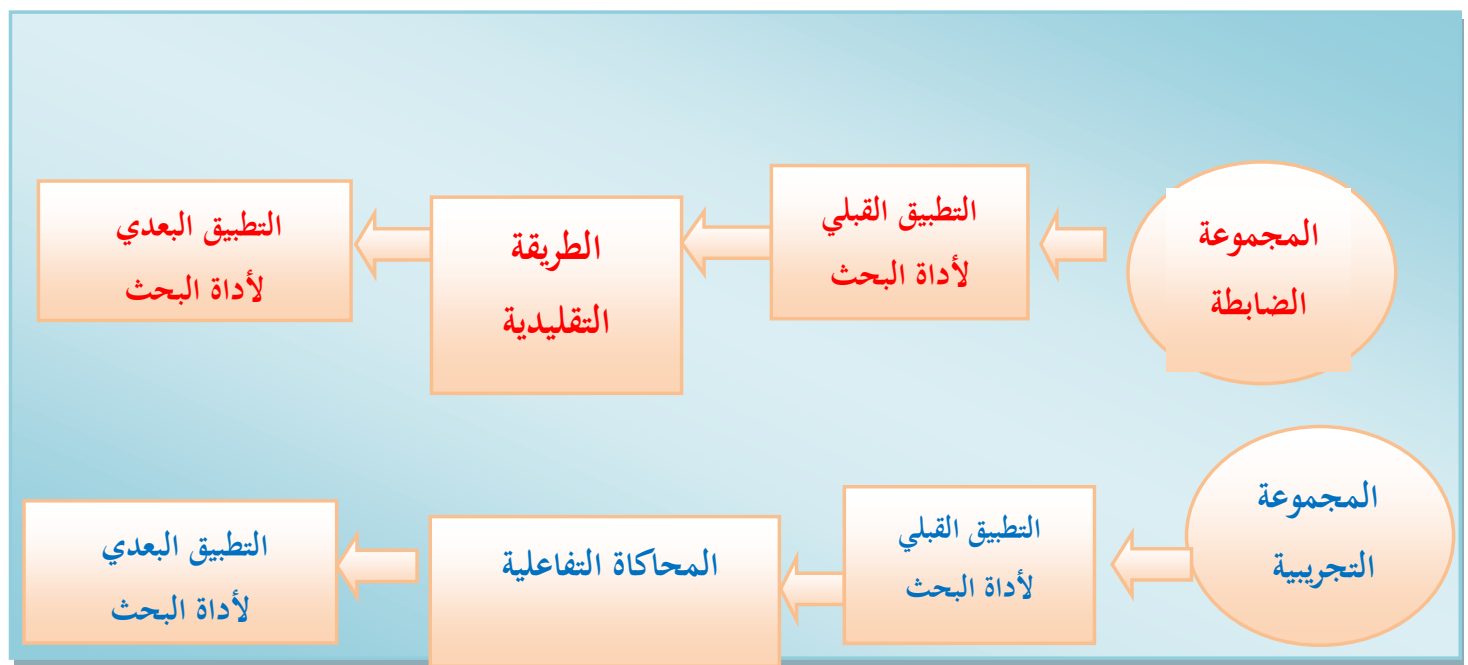

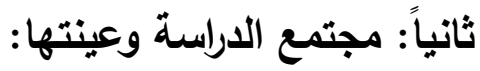


يتكون مجتمع البحث من طالبات الصف السادس بالمرحلة الإبتدائية بمدارس (آ7) خلال العام

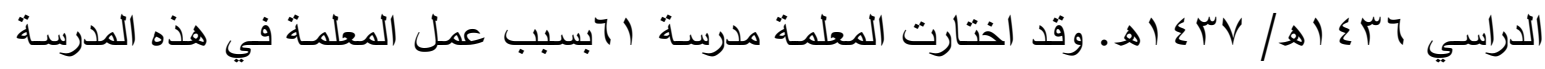
بوظيفة معلمة علوم. أما العينة تكونت من ( • ع) طالبة من طالبات الصف السادس الإبتدائي تم اختيارهن عشوائيا وتقسيمهما إلى مجموعتين، المجموعة الأولى وهي الضـابطة والمجموعة الثانية هي التجريبية، وبيلغ عدد كل مجموعه · r طالبة. صدق الاتساق الداخلي للاختبار: قام الباحثان بحسـاب الاتسـاق الداخلي للاختبار عن طريق حسـاب معـاملات الارتباط بين الدرجات التي حصل عليها الطالبات عينة الدراسة الاستطلاعية، وعددها ( • (ب) طالبة خارج عينة الدراسة، في كل جزء من أجزاء الاختبار ككل، وذلك باستخدام معامل بيرسون، ويتضح ذلك من الجدول التالي: (1) (1)

يبين معاملات الارتباط بين درجة كل فقرة من فقرات الاختبار والدرجة الكلية للاختبار

\begin{tabular}{|c|c|c|c|c|c|}
\hline مستوى الدلالة & معامل الارتباط & رقم السؤال & مستوى الدلالة & معامل الارتباط & رقم السؤال \\
\hline دالة & $* * .559$ & 1. & دالة & $* 0.305$ & 1 \\
\hline دالة & $* .423$ & 11 & دالة & $* * 0.451$ & r \\
\hline دالة & $* 0.289$ & Ir & دالة & $* * 0.512$ & r \\
\hline دالة & *0.380 & ir & دالة & $* * 0.418$ & $\varepsilon$ \\
\hline دالة & $* 0.337$ & $1 \leq$ & دالة & $* * 0.467$ & 0 \\
\hline دالة & *0.289 & 10 & دالة & $* 0.274$ & 7 \\
\hline دالة & $* * 0.449$ & 17 & دالة & *0.299 & v \\
\hline دالة & $* 0.315$ & IV & دالة & $* * 0.434$ & $\wedge$ \\
\hline دالة & $* * .426$ & 11 & دالة & $* 0.378$ & 9 \\
\hline
\end{tabular}

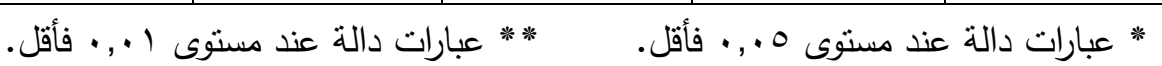
من الجدول السـابق يتضـح أن جميع العبارات دالة عند مستوى (1 . , ))، وبعضـها دال عند مستوى (0 • • • ) فأقل. وهو ما يوضح أن جميع الفقرات المكونة للاختبار تتمتع بدرجة صدق عالية، تجعله صالحة للتطبيق المبداني. 


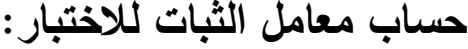

قام الباحثان بالتأكد من ثبات أداة الدراسـة من خـلال حساب معامل ألفا كرونباخ، والتجزئة النصفية، وجاءت النتائج كما يوضحها الجدول التالي:

جدول (r)

\begin{tabular}{|c|c|c|c|}
\hline التصفئة & كرونباخ & عدد الأسئلة & مقياس مهارات الاختبار \\
\hline 0.861 & $\cdot, \wedge \wedge 9$ & 11 & معامل الثبات للاختبار \\
\hline
\end{tabular}

يتبين من الجدول السابق أن قيم معامل ألفا كرونباخ للاختبار مرتفعة، حيث بلغ معامل الثبات الكلي

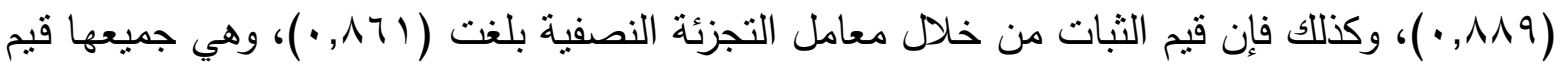
عاملات ثبات عالية تدل على ثبات الاختبار التحصيلي وصلاحيته للتطبيق الميداني.

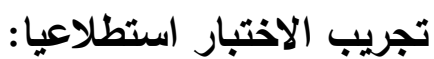

تم تجربة الاختبار استطلاعيا على العينة الاستطلاعية، بهذف تحديد الزمن المناسب للاختبار، وانتهت إلى تحديد زمن الاختبار المناس، حيث تم حساب الزمن المناسب للاختبار عن طريق حساب

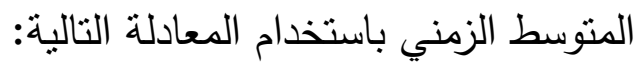
زمن انتهاء الطالبة الأولى + زمن انتهاء الطالبة الأخيرة r

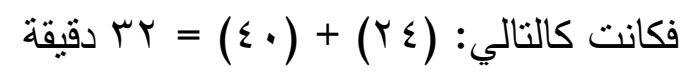

r

فأصبح زمن الاختبار بعد تطبيق المعادلة rr دقيقة يضاف إليها r دقائق لقراءة التعليمات

وللتحقق من تكافؤ المجموعتين التجريبية والضابطة على مقياس الاختبار التحصيلي قامت الباحثان باستخدام اختبار (ت) للعينات المستقلة، وجاءت النتائج كما يوضحها الجدول النالي:

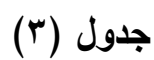

يبين دلالة الفروق بين متوسطات درجات تحصيل طالبات المجموعتين التجريبية والضابطة في التطبيق القبلي للاختبار التحصيلي بأبعاده المختلفة، وكنلك الارجة الكلية له 


\begin{tabular}{|c|c|c|c|c|c|c|c|}
\hline مستوى الدلاكة & لدرجات & قيمة (ت) & الانحراف & متوسط الدرجات & الطلاب & المجموعات & أبعاد مهارات الاختبار \\
\hline \multirow{2}{*}{ غير دالة 0.361} & \multirow[t]{2}{*}{38} & \multirow[t]{2}{*}{0.925} & 0.4867 & 0.500 & 20 & المجموعة الضابطة & \multirow[t]{2}{*}{ مهارة التذكر } \\
\hline & & & 0.3582 & 0.375 & 20 & المجموعة التجريبية & \\
\hline \multirow{2}{*}{ غير دالة 0.154} & \multirow[t]{2}{*}{38} & \multirow[t]{2}{*}{-1.453} & 0.3441 & 0.250 & 20 & المجموعة الضـابطة & \multirow[t]{2}{*}{ مهارة الفهم } \\
\hline & & & 0.3078 & 0.400 & 20 & المجموعة التجريبية & \\
\hline \multirow{2}{*}{ غير دالة 0.164} & \multirow[t]{2}{*}{38} & \multirow[t]{2}{*}{-1.418} & 0.3403 & 0.200 & 20 & المجموعة الضـابطة & \multirow[t]{2}{*}{ مهارة التطبيق } \\
\hline & & & 0.3285 & 0.350 & 20 & المجموعة التجريبية & \\
\hline \multirow{2}{*}{ غير دالة 0.442} & \multirow[t]{2}{*}{38} & \multirow[t]{2}{*}{-0.777} & 0.1832 & 0.075 & 20 & المجموعة الضابطة & \multirow[t]{2}{*}{ مهارة التحليل } \\
\hline & & & 0.2221 & 0.125 & 20 & المجموعة التجريبية & \\
\hline \multirow{2}{*}{$\begin{array}{l}1.000 \\
\text { غير دالة }\end{array}$} & \multirow[t]{2}{*}{38} & \multirow[t]{2}{*}{0.000} & 0.3403 & 0.300 & 20 & المجموعة الضابطة & \multirow[t]{2}{*}{ مهارة التركيب } \\
\hline & & & 0.3770 & 0.300 & 20 & المجموعة التجريبية & \\
\hline \multirow{2}{*}{ 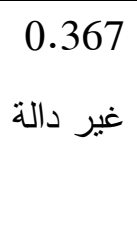 } & \multirow[t]{2}{*}{38} & \multirow[t]{2}{*}{-0.913} & 0.8156 & 1.325 & 20 & المجموعة الضابطة & \multirow{2}{*}{ لمهارات الاختبار } \\
\hline & & & 0.7416 & 1.550 & 20 & المجموعة التجريبية & \\
\hline
\end{tabular}

بالنظر إلى الجدول السابق يتضح عدم وجود فروق ذات دلالة إحصائية عند مستوى دلالة (0., •) بين طلاب المجموعة التجريبية والضابطة في التطبيق البعدي لأبعاد (التذكر، الفهم، التطبيق، التحليل،

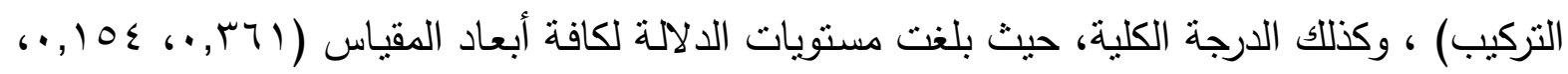

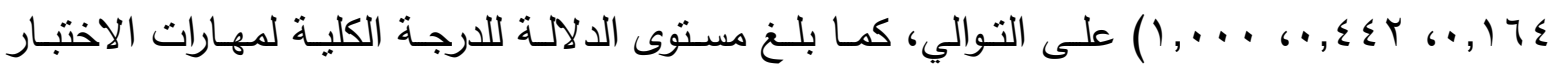
(VTr, • • مما يبين تكافؤ المجموعتين في النطبيق القبلي لمهارات الاختبار التحصيلي وبالتالي إمكانية إجراء التجربة على مجموعتي الدراسة نظراً لتحقق شرط التجانس في المستوى التحصيلي. ثالثاً: تصميم المعالجة المقترحة:

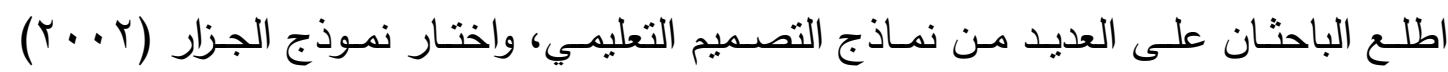
للتصميم التعليمي وقد تم إتباع المراحل التالية: المرحلة الأولى: مرحلة التحليل (Analysis): هذه المرحلة هى نقطة البدء فى خطوات النموذج، حيث تم فى هذه المرحلة بتحديد خصائص المتعلمات، طالبات الصف سادس الإبتدائي وتحديد الحاجات التعليمية، ودراسة الواقع الذي سيتم فيه 
النطبيق باستخدام المحاكاة التفاعلية الموجودة في المنصة التعليمية الثثلثية الابعاد المقترحة ومصادر التعلم المتوفرة والمتعلقة بالموضوع، وفيما يلى عرض لخطوات هذه المرحلة: 1 - 1 - تحديد خصائص الطالبات: تتحدد خصائص الطالبات فيما يلي:

- متوسـط أعمارهن تــراوح مـا بـين

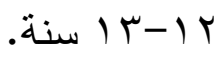
- - - طالبات بالصف الساد الإبندائى. - لديهن خبرة فى التعامل مع الحاسب.

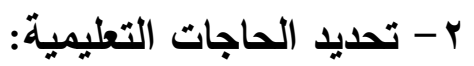

تتحدد الحاجات التعليمية في تتمية المفاهيم العلمية المادة العلوم حيث تُشكل معالجتها أثر فعال رفع المستوى تعليمي لذلك كان لابد من تطبيق تقنية تعليمية تتتاسب مع خصائص المتعلمات، بشكل يجعلهم أكثر تجاوبا معها وتتمثل هذه التقنية باستخدام المحاكاة التفاعلية، وبناء على ذلك تم تحديد المفاهيم التى تتضمنها الوحدة المختارة من كتاب الطالبة فى مادة العلوم.

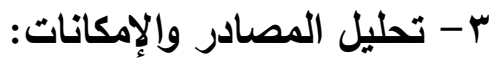
تم القيـام بمسـح شـامل للوسـائل والمصـادر التعليميـة الخاصـة بالتـدريس مـن خـلال اسـتخدام المحاكاة التفاعلية المقترح المرحلة الثانية: مرحلة التصميم (Design):

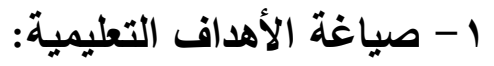

تتم صياغة الاهداف التعليمية الاجرائية، وقد استعانت الباحثان بموقع وزارة التربية والتعليم وهي كما يلي: - n - أن يعرف الطالب عملية الهضم. - أن يعددا لطالب أجزاء الجهاز التتفسي. - إن يشرح الطالب وظيفة الجهاز التتفسي. - إن يقارن الطالب بين الجهاز التنفسي وجهاز - إن يلخص الطالب عمل الدورة الدموية. الإخراج. - إن يوضح الطالب عمل الأمعاء الدقيقة. - إن ينسب الطالب العليات الحيوية غالى الأجهزة المناسبة لها.

- أن يرتب الطالب الكلمات التالية للحصول على مفهوم الإخراج (الفضلات - تخليص - الجسم - 


\section{r - تحديا المحتوى التعليمى:}

وفقاً لتقسيم الدروس المعتمد من وزارة التربية والتعليم، تم اختيار وحدة عمليات الحياتواختيار درس أجهزة الدوران والنتفس والهضم لاحتوائـة على عدد من الدفاهيم والموضـوعات التي تتاسب المحاكاة التفاعلية الموجودة في المنصد التعليمية الثلاثية الأبعاد المقترحة. r- تصميم الاستراتيجية التعليمية:

استهدفت هذه الخطوة تصميم استراتيجية التعلم وأنشطته التى تقوم على توظيف المحاكاة التفاعلية المقترح. حيث تم تحديد الإجراءات والخطوات المختلفة لتقديم المحتوى التعليمي، وتحديد طرق تقديم الأنشطة والتفاعلات التعليمية. اختارت الباحثان إستراتيجية التعلم والأنشطة التعليميـة، حيث يتت البدء بمقدمـة عن موضوع البه الدرس، ثم يبـأ عرض المحتوى وتتخللـه الأنشطة والاختبـارات المرحليـة مـع تقديم التخذيـة الراجعـة المناسبة، وفي حال الإتقان تنتقل المتعلمة إلى الجزء التالي وهكذا حتى إتمام كافة الأجزاء والثكل (r) يوضح الإستراتيجية المستخدمة. شكل (ॅ): إستراتيجية تطلم باستخدام المحاكاة التفاعلية ثلاثة الأبعاد

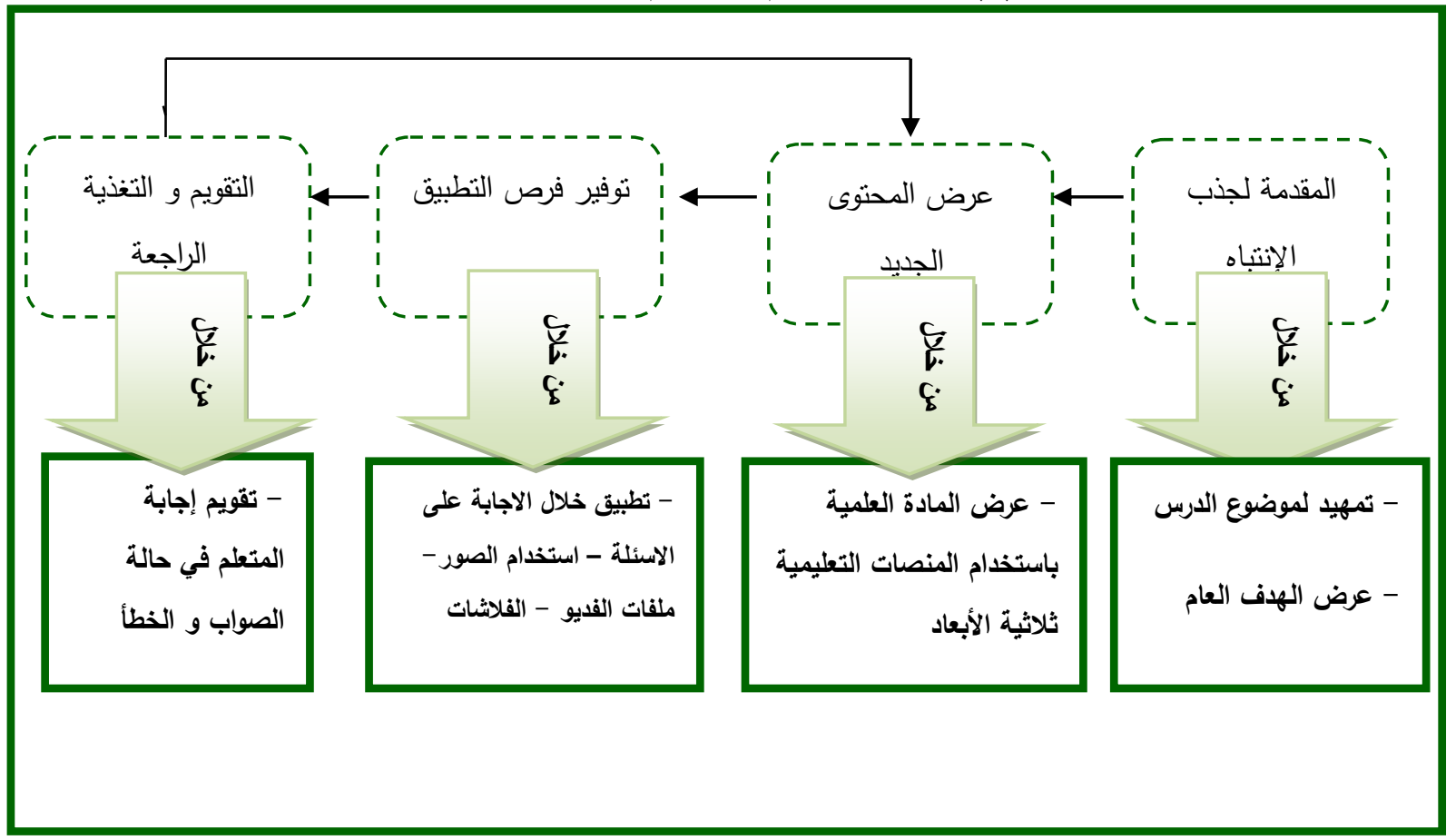


- استحواذ انتباه الطالبات: تم تحقيق ذلك باستخدام المحاكاة التفاعلية المقترحة باستخدام الصور الثابتة والمتحركة والألوان والأصوات المناسبة لاهنمامات الطالبات والمحتوى والمرحلة العمرية. - تعريف الطالبات بأهداف التعلم: بعد تقديم المقدمة باستخدام المحاكاة التفاعلية المقترحة يوجد شاشة خاصة بأهداف التعلم والهدف من استخدام المحاكاة التفاعلية المقترح، وكذلك بعد كل درس حيث تم من خلالها توضيح أهداف التعلم بطريقة مبسطة ومناسبة للطالبات مع مراعاة الاختصار في تقديمها. - عـرض المثيـرات: تمثلت في عناصـر المحاكـاة التفاعليـة المقترحـة مـن فيديوهات وصـور وفلاشات وعروض بور بينت وملخصات وأسئلة.

\section{ع - تحديد مهام التدريب وأنشطته:}

ويتم في هذه الخطوة تحديد مهام التدريب وأنشطته التي يجب على المتعلمات إنجازها في التعليم باستخدامهم المحاكاة التفاعليةالثلاثيـة الأبعاد المقترحة حيث تتاولت تدريبهم على استخدام المنصـه التعليمية التثلاثية الأبعاد المقترحة، وتصميم الأنشطة التدربيية التي كانت مرتبطة بالأهداف الإجرائية للدرس. 0 - تصميم السيناريو: تم اختيارالمحاكـاة التفاعليـة لخدمـة تعلـم درس (الهضــم والإخـراج والتنفس والـدوران)، وتحقيـق أهدافها التعليمية. تم ترتيب المحتوى في شكل ملفات متنوعة تم تصميمها (مثنل: ملفات فديوات ملفات فلاشات - ملفات عروض بور بينت- ملفات ملخصات ورد - ملفات صور - ملفات أسئلة) هذا وقد راعت الباحثان عند اختيار المنصّـة التعليميـة الثلاثيـة الأبعاد المقترحة الجوانب التصميمية التالية للمنصيّات التعليمية وهي:

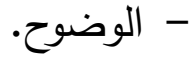 - البساطة وعدم التعقيد. -

- التتــوع فـــي محتويـــات المحاكــــاة التفاعلية. - ارتباط محتوى المحاكاة التفاعلية بأهداف الوحدة التعليمية. - الترتيب الملفات السهولة الاستخدام.

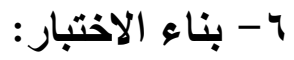


تم أعداد اختبار في ضوء الأهداف التي تم تحديدها في الخطوة الأولى من مرحلة التصميم وتم مرور الاختبار على المحكمين وتم الرد وقد استغرق الرد اسبوعين وقد تم بناءوتعديل الاختبار حسب اراء المحكمين. تم تقديم الإختبار بشكل ورقي ويشمل فقرة من نوع الإختيار من متعدد، وأسئلة تتضمن الصواب والخطاء، وتوصبل بالعمود (أ) بما بنسبه من العمود (ب). - الهرف من الإختبار : يهدف الاختبار إلى قياس تحصيل طالبات الصف السادس لمفاهيم الهضم والإخراج والتنفس والدوران. - إعداد جدول المواصفات: تم إعداد جدول المواصفات للاختبار وذلك للربط بين الأهداف التعليمية وبين المحتوى. جدول (r) جدول المواصفات للاختبار

\begin{tabular}{|c|c|c|c|c|c|c|c|}
\hline \multicolumn{8}{|c|}{ الأهداف } \\
\hline التقويم & التركيب & التحليل & التطبيق & الفهم & التذكر & الأهداف & الموضوع \\
\hline-- & 1 & 1 & 1 & $r$ & $r$ & $\wedge$ & والهضم \\
\hline- & 1 & 1 & 1 & r & $r$ & للمهارة & الارجة ال \\
\hline- & $\%$ Ir & $\% 1 r$ & $\% 1 r$ & $\%$ ro & $\% r v$ & للمهارة & الوزن الن \\
\hline
\end{tabular}
- تحديد نوع الاختبار وصياغته: بالنسبة لنوع الاختبار ، فقد كان الاختبار موضوعياً، وذلك للأسباب التالية: - خلوه من التأثر بذاتية المصحح ويقلل نسبة التخمين. - تغطيته جزء كبير من المادة العلمية المراد اختبار الطالبات فيها. - لله معدلات صدق وثبات عالية. 
تم مراعاة وضوح العبارات وبساطتها عند بناء فقرات الإختبار وصياغتها وتمثل الإختبار في ثلاثة أنواع من الأسئلة: الصواب والخطأ، ومتعدد الاختيارات وقد كان لكل مفردة من مفردات الاختبار أربعة بدائل تحوى في طياتها الإجابة الصحيحة، وتوصيل بالعمود (أ) بما يناسبه من العمود (ب).

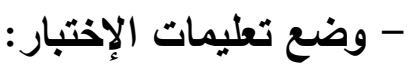
تضمنت التعليمات الخاصة بالاختبار ، نسجيل الاسم والدجوعة، وكيفية الإجابة عليه، والتأكيد

$$
\text { - على ضرورة الإجابة عن جميع الأسئلة. }
$$$$
\text { تم إعداد ورقة الإجابة على الاختبار للإجابة على أسئلة }
$$

V - خطوات المعالجة التجريبية للاراسة: - v

تم تطبيق المعالجة تجريبية وفقا الخطوات التالية:

ا ـ تم ارسال الاختبار إلى عدد من المكمين وقد استغرق الرد من المحمكين اسبوعان وتم تعديل

الاسئلة بناء على اراء المحكمين واقتراحاتهم.

r. تم التوجة لمكتب التطوير لنسهيل مهمة الباحثان للمدرسة.

r. تمت الموافقة على التطبيق من قبل المدرسة.

ـ. تم عمل عينـة استطلاعية لـ . r طالبة وتطبيق الاختبار على العينـة الاستطلاعية بتاريخ



المجموعة ضابطة والفصل الثاني المجموعة تجريبية.

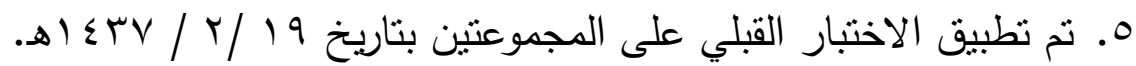

T. تم تقديم الدرس، حيث اتبعت المجموعة الضابطة طريقة التدريس الثقليدية، ومع المجموعة التجريبية باستخدام المحاكاة التفاعلية المقترحة واستمر لتدريس خلال حصتان لكل مجموعه

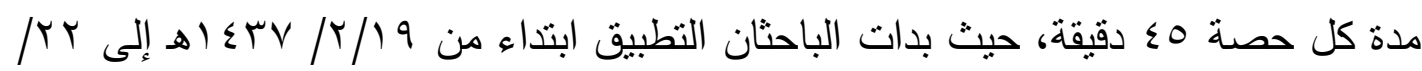

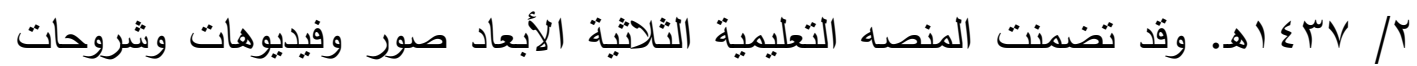
وتتريح لأجزة الجسم تفوق مستوى الطلاب ولذلك تم اختيار الأجزاء التي تتاسب طلاب

$$
\text { الصف السادس والصور المناسبة للفئة العمرية }
$$

$$
\text { V. تم تطبيق الاختبار البعدي على طالبات المجموعتين. }
$$


تتكل عملية حساب معامل السهولة والصعوبة لكل فقرة من فقرات المقياس عملية ضرورية ومهمة

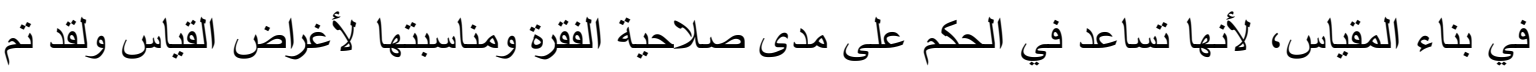

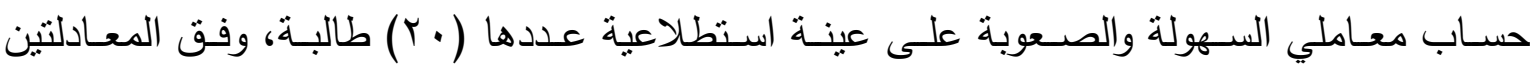

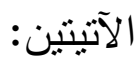
معامـل السـهولة = عـد الإجابـات الصـحيحة ٪ (عـد الإجابـات الخاطئة + عـدد الإجابـات الصحيحة). معامل الصعوبة = (- معامل السهولة

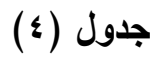

\begin{tabular}{|c|c|c|c|c|}
\hline معامل الصعوبة & معامل السهولة & عدد الإجابات الخطأ & عدد الإجابات الصحيحة & رقم السؤال \\
\hline 0.40 & 0.60 & 8 & 12 & -1 \\
\hline 0.50 & 0.50 & 10 & 10 & $-r$ \\
\hline 0.35 & 0.65 & 7 & 13 & r \\
\hline 0.35 & 0.65 & 7 & 13 & $-\varepsilon$ \\
\hline 0.30 & 0.70 & 6 & 14 & -0 \\
\hline 0.35 & 0.65 & 7 & 13 & -7 \\
\hline 0.30 & 0.70 & 6 & 14 & $-v$ \\
\hline 0.25 & 0.75 & 5 & 15 & $-\lambda$ \\
\hline 0.40 & 0.60 & 8 & 12 & -9 \\
\hline 0.30 & 0.70 & 6 & 14 & -1 \\
\hline 0.45 & 0.55 & 9 & 11 & -11 \\
\hline 0.50 & 0.50 & 10 & 10 & -14 \\
\hline 0.55 & 0.45 & 11 & 9 & $-1 \mu$ \\
\hline 0.40 & 0.60 & 8 & 12 & $-1 \leqslant$ \\
\hline 0.50 & 0.50 & 10 & 10 & -10 \\
\hline 0.30 & 0.70 & 6 & 14 & -17 \\
\hline 0.30 & 0.70 & 6 & 14 & $-1 \mathrm{~V}$ \\
\hline 0.35 & 0.65 & 7 & 13 & -11 \\
\hline
\end{tabular}


من الجدول السـابق يتضح أن القيمة مقبولة في معظهها وأن معاملات السهولة لاختبار التحصيل الدراسي تراوحت بين (0.75، 0 ؛ , •) ، وهذا يدل على أن اختبار التحصيل الدراسي معتدل السهولة، بينما كانت معاملات الصعوبة للاختبار تراوحت بين (0, •، 00, •) ، وهذا يدل على أن الاختبار معتدل الصعوبة، واقتراب المعاملات من (0, ·) المعبرة عن مناسبة مفردات اختبار التحصيل الدراسي لري اعتمادا على أن القيمة السابقة متوسطة تعبر عن التوازن في فقرات اختبار التحصيل الدراسي من من من حيث السهولة والصعوبة. نتائج الاراسة وتوصياتها

في هذا الفصل يعرض الباحثان نتائج تحليل بيانات الدراسـة التي توصلت إليها، بتطبيق أداة الدراسة، بالإضافة إلى مناقتتها وتفسيرها، ومقارنتها بنتائج بعض الدراسات السابقة. أولاً: عرض نتائج الدراسة: الإجابة على تساؤل الاراسة:

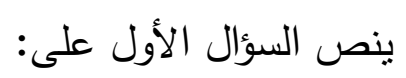

هل هناك فروق دالة إحصائياً بين منوسطي درجات المجموعة الضابطة الني تعلدت بالطريقة

التقليدية، وبين المجموعة التجريبية التي تعلمت باستخدام المحاكاة التقاعلية؟ للإجابـة على النساؤل، والتحقق من مدى وجود فروق دالـة إحصـائياً بين متوسطي درجات المجموعة الضـابطة التي تعلمت بالطريقة التقليدية، وبين المجموعة التجريبية التي تعلمت باستخدام المحاكاة التفاعلية، تم الإجابة على التساؤلات الفرعية المندرجة تحت هذا التساؤل على النحو الثالي:

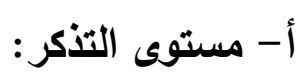
للتعرف على ما إذا كانت هناك فروق ذات دلالة إحصائية عند مستوى (ه*. متوسطي درجات طالبـات المجموعـة التجريبيـة وطالبـات المجموعـة الضـابطة في النطبيق البعدي للاختبار التحصيلى لمستوى التذكر ، استخدم الباحثان اختبار (ت) للعينات المستقلة ( Independent Samples Test )،للتعرف على الفروق بالنسبة للمجموعتين التجريبية والضـابطة في النطبيق البعدي، وهو ما يوضحه الجدول التالي: - 20 


\section{جدول (•) - (•)}

اختبار (ت) للعينات المستقلة لدلالة الفروق بين متوسطات طالبات المجموعة التجريبية والضابطة في التطبيق البعدي لمستوى التذكر

\begin{tabular}{|c|c|c|c|c|c|c|c|}
\hline مستوى الدلالة & لدرجات & قيمة (ت) & الانحراف المعياري & الدرجات & الطالبات & مجموعات الدراسة & التاختبار \\
\hline \multirow{2}{*}{ 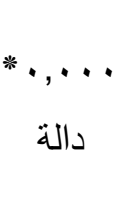 } & \multirow[t]{2}{*}{ rی } & \multirow[t]{2}{*}{-10.315} & 0.41039 & 1.200 & $r \cdot$ & الضابطة المجوعة & \multirow[t]{2}{*}{ التذكر } \\
\hline & & & 0.44721 & 2.600 & $r$. & البحموعة التجريبية & \\
\hline
\end{tabular}

بالنظر إلى الجدول السـابق يتضـح تفوق طالبات المجموعة التجربيية على طالبات المجموعة الضابطة في التطبيق البعدي للاختبار لمستوى التذكر ، حيث بلغ متوسط درجات طالبات المجموعة التجريبية في التطبيق البعدي ( . . r, r) ، بينما بلغ متوسط درجات طالبات المجموعة الضـابطة في

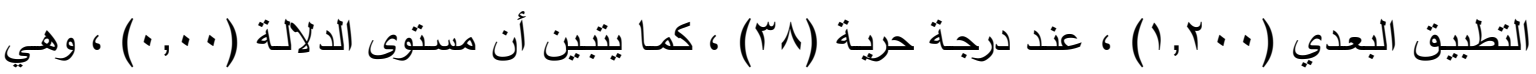
قيمـة دالـة إحصـائياً عند مسـتوى دلالـة (ه *.

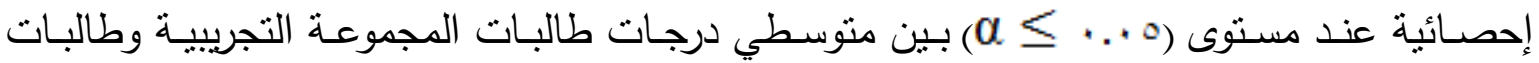
المجموعة الضـابطة في مستوى التذكر فى الاختبار التحصيلي لصالح طالبات المجموعة التجريبية. ومن ثم تم الإجابة على السؤال، والتحقق من صحة الفرض فى الجزء الخاص بمستوى التذكر . ويفسرها الباحثان تلاك النتيجة بأن التعليم باستخدام المحاكاة التفاعلية يساعد الطالبات في تبادل الأفكار والآراء وبالتالي زيادة مستوى التذكر للمادة العلمية، كما أنه يؤدي إلى تتمية مستوى الإبداع لدى الطالبات.

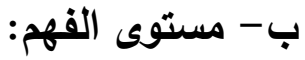

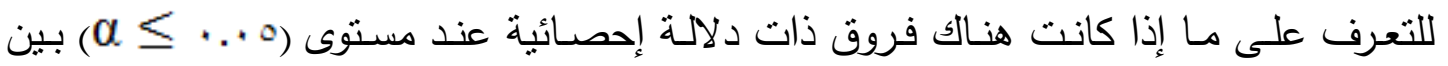
متوسطي درجـات طالبـات المجموعـة التجريبيـة وطالبـات المجموعـة الضـابطة في التطبيـق البعدي للاختبار التحصيلى لمستوى الفهم، استخدم الباحثنان اختبار (ت) للعينات المستقلة ( Independent 
(Samples Test ، للتعرف على الفروق بالنسبة للمجموعتين التجريبية والضـابطة في التطبيق البعدي، وهو ما يوضحه الجدول التالي:

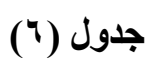

اختبار (ت) للعينات المستقلة لالالة الفروق بين متوسطات طالبات المجموعة التجريبية والضابطة في التطبيق البعدي لمستوى الفهم

\begin{tabular}{|c|c|c|c|c|c|c|c|}
\hline مستوى الدلالة & الحرية & قيمة (ت) & الانحراف المعياري & متوسط الدرجات & الطالبات & مجموعات & التحصيلي الاختبار \\
\hline \multirow{2}{*}{ 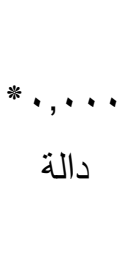 } & \multirow{2}{*}{ ґᄉ } & \multirow{2}{*}{-16.616} & 0.20520 & 0.600 & $r$. & الضمابطة الموعة & \multirow{2}{*}{ لفهم } \\
\hline & & & 0.27506 & 1.875 & $r$. & التجريبية & \\
\hline
\end{tabular}

* دالة عند مستوى (0. . • (•)

بالنظر إلى الجدول السـابق يتضـح تفوق طالبات المجموعة التجربيية على طالبات المجموعة الضـابطة في التطبيق البعدي في مستوى الفهم على الاختبار التحصيلي حيث بلـغ متوسط درجات

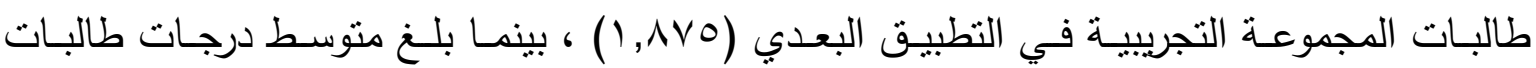

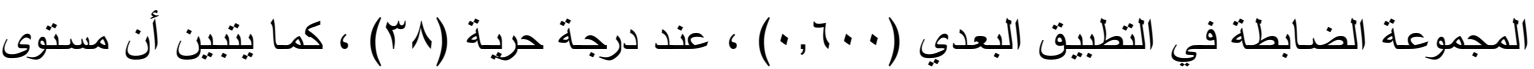

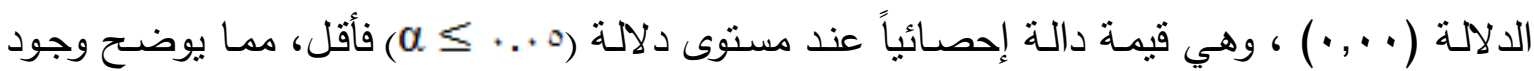

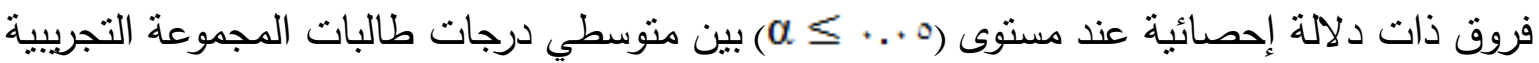
وطالبـات المجموعـة الضـابطة في مستوى الفهم فى الاختبـار التحصـيلي لصـالح طالبـات المجموعـة التجريبية. ومن ثم تم الإجابة على السؤال، والتحقق من صحة الفرض فى الجزء الخاص بمستوى الفهم. ويفسرها الباحثان نلك النتيجة بأن التعليم من خلال المحاكاة التفاعلية يساعد في سهولة عرض المادة العلمية كما أن المثيرات التي يحتويها المحاكاة التفاعلية تسرل على الطالبات فهم محتوى المادة العلمية.

\section{ج- مستوى التطبيق} للتعرف على مـا إذا كانـت هناك فروق ذات دلالـة إحصـائية عند مسـتوى (ه.. متوسـطي درجـات طالبـات المجموعـة التجربيـة وطالبـات المجموعـة الضـابطة في التطبيـق البعدي 
لاختبار التحصيلى لمستوى التطبيق، استخدم الباحثنان اختبار (ت) للعينات المستقلة ( Independent (Samples Test ، للتعرف على الفروق بالنسبة للمجموعتين التجريبية والضـابطة في التطبيق البعدي، وهو ما يوضحه الجدول التالي:

\section{جدول (V)}

اختبار (ت) للعينات المستقة لالالة الفروق بين متوسطات طالبات المجموعة التجريبية والضابطة في التطبيق البعدي لمستوى التطبيق

\begin{tabular}{|c|c|c|c|c|c|c|c|}
\hline مستوى الدلالة & درجات & قيمة (ت) & الانحراف & متوسط الدرجات & الطالبات & مجموعات الدراسة & أبعاد الاختبار \\
\hline \multirow{2}{*}{$\begin{array}{c}\text { *., . . } \\
\text { دالة }\end{array}$} & \multirow{2}{*}{ rᄉ } & \multirow{2}{*}{-7.177} & 0.20520 & 0.600 & $r$. & البحموعة الضابطة & \multirow{2}{*}{ التطبيق } \\
\hline & & & 0.11180 & 0.975 & $r$. & البحموعة التجرييية & \\
\hline
\end{tabular}

* دالة عند مستوى (0. . • (•)

بالنظر إلى الجدول السـابق يتضـح تفوق طالبات المجموعة التجربيية على طالبات المجموعة الضابطة في التطبيق البعدي في مستوى التطبيق على الاختبار التحصيلي حيث بلغ متوسط درجات طالبـات المجموعـة التجريبيـة في التطبيـق البعدي (9V0, • ) ، بينمـا بلـن متوسـط درجـات طالبـات

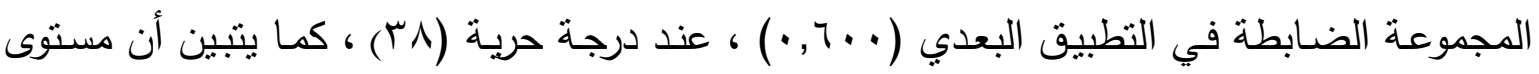

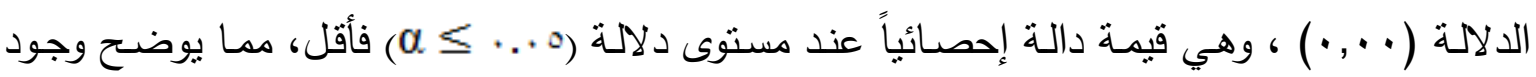

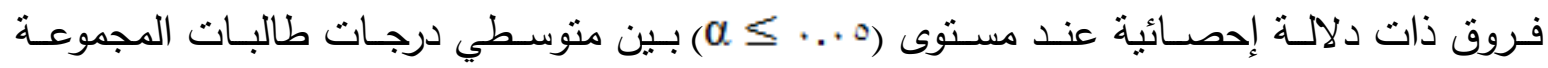
التجربيبـة وطالبـات المجموعـة الضـابطة في مستوى الفهم فى الاختبـار التحصـيلي لصـالح طالبـات المجموعة التجريبية. ومن ثم تم الإجابـة على السؤال والتحقق من صحة الفرض فى الجزء الخاص بمستوى التطبيق. ويفسرها الباحثان تلك النتيجة بأن من استخدام المحاكاة التفاعلية بيساعد الطالبات من خـلال عملية النمذجة في زبادة قدرات الطالبات على التطبيق، الأمر الذي يؤدي إلى زيادة مستوى الوعي والإدراك لديهن.

$$
\text { د - مستوى التحليل }
$$

للتعـرف على مـا إذا كانت هنـالك فروق ذات دلالـة إحصـائية عند مسـتوى (ه .. متوسطي درجـات طالبـات المجموعـة التجريبيـة وطالبـات المجموعـة الضـابطة في التحليـل البعـي 
للاختبار التحصيلى لمستوى التحليل، استخدم الباحثنان اختبار (ت) للعينات المسنقلة ) Independent (Samples Test ، للتعرف على الفروق بالنسبة للمجموعتين التجريبية والضابطة في التحليل البعدي، وهو ما يوضحه الجدول التالي:

جدول (^)

اختبار (ت) للعينات المستقة لدلالة الفروق بين متوسطات طالبات المجموعة التجريبية والضابطة في التحليل البعدي لمستوى التحليل

\begin{tabular}{|c|c|c|c|c|c|c|c|}
\hline مستوى الدلالة & درجات & قيمة (ت) & الانحراف & الارجات & علداد & مجموعات الدراسة & أبعاد الاختبار \\
\hline$*, \ldots$ & \multirow{2}{*}{ rᄉ } & \multirow{2}{*}{-19.000} & 0.00000 & 0.500 & $r$. & المجموعة الضابطة & \multirow{2}{*}{ التحليل } \\
\hline دالة & & & 0.11180 & 0.975 & $r$. & المجموعة التجريبية & \\
\hline
\end{tabular}

* دالة عند مستوى (0. . • (•)

بالنظر إلى الجدول السـابق يتضـح تفوق طالبات المجموعة التجريبية على طالبات المجموعة الضابطة في التحليل البعدي في مستوى التحليل على الاختبار التحصيلي حيث بلـغ منوسط درجات طالبـات المجموعـة التجريبيـة في التحليـل البعدي (9V0, • ) ، بينمـا بلـغ متو سط درجـات طالبـات

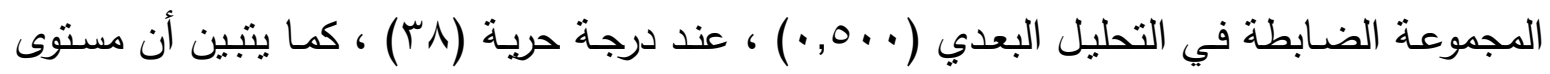

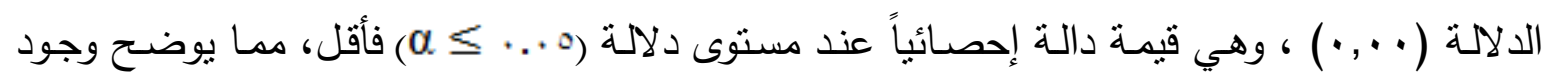

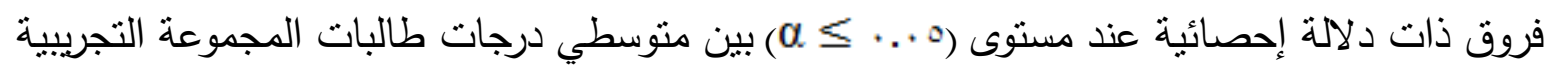
وطالبات المجموعـة الضـابطة في مستوى الفهم في الاختبار التحصيلي لصـالح طالبات المجموعة التجريبيـة. ومن ثم تم الإجابـة على السؤال والتحقق من صسحة الفرض في الجزء الخاص بمستوى التحليل. ويفسـرها الباحثنان تلك النتيجـة بـأن مـن مميـزات اسـتخدام المحاكـاة التفاعليـة هـو زبـادة قدرة الطالبات على فهم المادة العلمية وبالتالي زيادة القدرة على تحليل محتواها العلمي وإمكانية الربط بين المادة العلمية وفهم محتواها. هـ - مستوى التركيب للتعـرف على مـا إذا كانت هنـالك فروق ذات دلالـة إحصـائية عند مستوى (ه *.. متوسطي درجـات طالبـات المجموعـة التجريبيـة وطالبـات المجموعـة الضـابطة في التركيب البعدي 
للاختبار التحصيلى لمستوى التركيب، استخدم الباحثنان اختبار (ت) للعينات المستقلة ( Independent (Samples Test ، للتعرف على الفروق بالنسبة للمجموعتين التجريبية والضـابطة في التركيب البعدي،

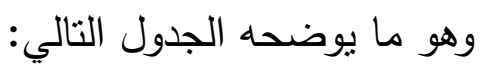

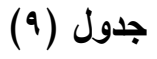

اختبار (ت) للعينات المستقلة لدلالة الفروق بين متوسطات طالبات المجموعة التجريبية والضابطة في التركيب البعدي لمستوى التركيب

\begin{tabular}{|c|c|c|c|c|c|c|c|}
\hline مستوى الدلالة & الحرية & قيمة (ت) & الانحراف & الدرجات & الطالبات & مجموعات الدراسة & أبعاد الاختبار \\
\hline \multirow{2}{*}{ دالة • , . . } & \multirow{2}{*}{ rᄉ } & \multirow{2}{*}{-4.660} & 0.22213 & 0.625 & $r$. & الضمابطوعة & \multirow{2}{*}{ التركيب } \\
\hline & & & 0.18317 & 0.925 & $r \cdot$ & التجريبية & \\
\hline
\end{tabular}
* دالة عند مستوى (0. • (•)

بالنظر إلى الجدول السـابق يتضـح تفوق طالبات المجموعة التجريبية على طالبات المجموعة الضابطة في التركيب البعدي في مستوى التركيب على الاختبار التحصيلي حيث بلغ متوسط درجات

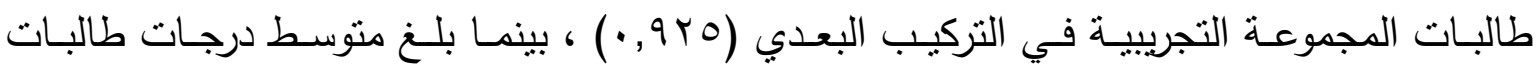

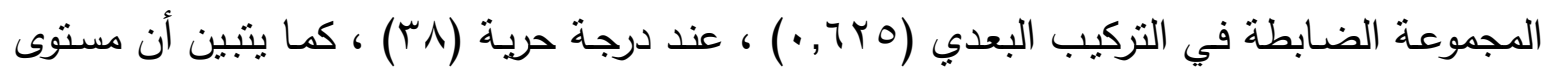
الدلالة ( · , • ) ، وهي قيمة دالة إحصـائياً عند مستوى دلالة (ه ...

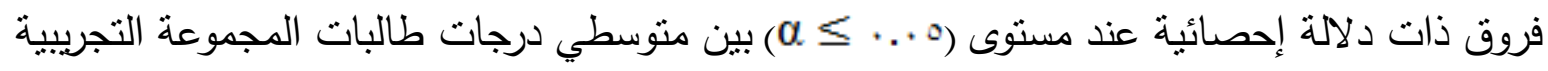
وطالبـات المجموعـة الضـابطة في مستوى الفهم في الاختبار التحصيلي لصـالح طالبات المجموعـة التجريبية. ومن ثم تم الإجابـة على السؤال والتحقق من صسحة الفرض في الجزء الخاص بمستوى التركبب.

ويفسرها الباحثنان تلك النتيجـة بـأن التعليم مـن خـلال المحاكـاة التفاعليـة يتيح فرصـاً متوازيـة للطالبـات في عمليـة التعرف على المـادة العلميـة، كمـا أنه يسـاعد الطالبات في التعرف على أجزاء المحتوى التعليمي وبالتالي يؤدي إلى زيادة قدرة الطالبات نحو التعرف على أجزاء المحتوى التعليمي، والقدرة على تركيب هذه الأجزاء لتكون شكلاً معروفاً في مادة الأحياء. 


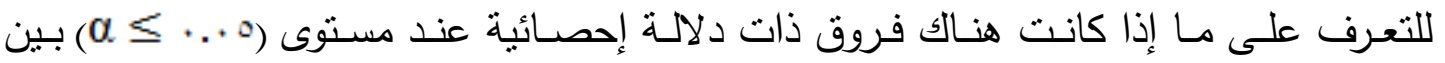
منوسطي درجات طالبـات المجموعـة التجريبية وطالبـات المجموعـة الضـابطة في النطبيق البعدي للاختبار التحصيلى ككل، استخدم الباحثان اختبار (ت) للعينات المستقلة ( Independent Samples (Test ، للتعرف على الفروق بالنسبة للمجموعتين التجريبية والضابطة في التطبيق البعدي، وهو ما

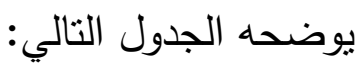

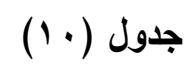

اختبار (ت) للعينات المستقلة لالالة الفروق بين متوسطات طالبات المجموعة التجريبية والضابطة في التطبيق

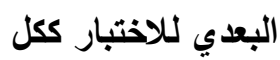

\begin{tabular}{|c|c|c|c|c|c|c|c|}
\hline الدالة & الرجرية & قيمة (ت) & الانحراف & متوسط & الطالبات & مجموعات & أبعاد الاختبار \\
\hline$*, \ldots$ & \multirow{2}{*}{ rᄉ } & \multirow{2}{*}{-7.210} & 0.65845 & 3.525 & r. & الضابطة & \multirow{2}{*}{ للاختبار الارجة الكلية } \\
\hline دالة & & & 3.78875 & 9.725 & r. & التجريبية & \\
\hline
\end{tabular}

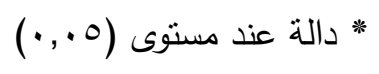

بالنظر إلى الجدول السـابق يتضـح تفوق طالبات المجموعة التجريبية من طالبات المجموعة الضابطة في التطبيق البعدي في الدرجة الكلية لمهارات الاختبار التحصيلي حيث بلغ منوسط درجات طالبـات المجموعـة التجريبيـة في النطبيق البعدي (9,VYO) ، بينمـا بلـن متوسط درجـات طالبـات

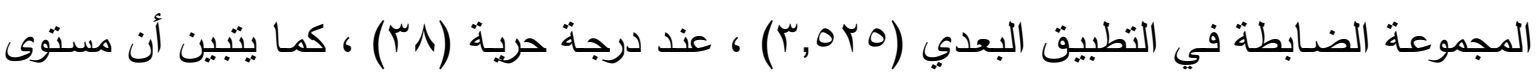

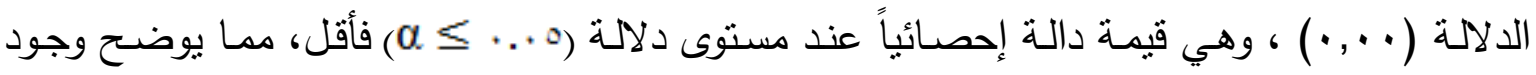
فروق ذات دلالة إحصائية عند مستوى (ه .. ك ع) بين منوسطي درجات طالبات المجموعة التجريبية وطالبات المجموعة الضـابطة في اجمالى الاختبار التحصيلي لصالح طالبات الهموعـة التجريبية. ومـن ثم تم الإجابـة على السؤال الأول، والتحقق مـن صـحة الفرض فـى الجزء الخـاص باجمـالى

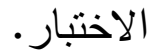
فى ضوء ما تم عرضه يتضح اثبات صحة الفرض الأول بشكل كامل وقبوله، حيث تبين وجود

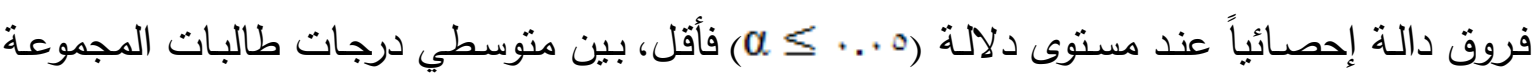


التجريبية وطالبات المجموعة الضـابطة في كل من: مستوى التذكر، مستوى الفهم، مستوى التطبيق، ومستوى التحليل، ومستوى التركيب، والاختبار ككل لصالح طالبات المجموعة التجريبية. وتتفق هذه النتيجة مـع العديد من الدراسـات السـابقة، ومنها مـا دراسـة (الديك، • rم) التي توصلت إلى أنه توجد فروق ذات دلاله احصائيه بين متوسطات تحصيل طلبة الصف الحادي عشر العلمي ومتوسطات اتجاهاتهم نحو تعلم الميكانيكا.

كما اتفقت مع دراسة (أبو السعود، 9 . . rم) التي توصلت إلى وجود فروق ذات دلاله احصائيه بين متوسطات درجات طلبة المجموعه التجريبية والضابطة في القياس البعدي لمهارات ماوراء المعرفه لصالح طلبة المجموعه التجريبية كما توجد فروق ذات دلاله احصائيه بين متوسطات درجات طالبات المجموعتين التجربيية والضابطة في القياس البعدي لمهارات ماوراء المعرفه لصالح طالبات المجموعه التجريبية.

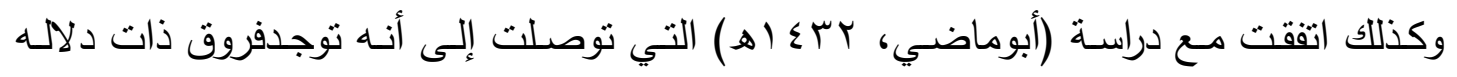
احصائيه عند مستوى (0,05) بين متوسط درجات طالبات الجموعد التجريبية ومتوسط درجات طالبات المجموعه الضابطة في الاختبار المعرفي للمفاهيم والمهارات الكهربيه وفي بطاقه الملاحظه للمهارات الكهربيه، كما توصلت الدراسة إلى وجود فروق ذات علاقة ارتباطيه موجبه الأشاره ومتوسطه القيمه (0,53) بين درجات طالبات المجموعتين في الاختبار المعرفي لمفاهيم والمهارات الكهربيه وبطاقه الملاحظه للمهارات الكهربيه. كما اتفقت مـع دراسـة (محمد، ( • ب) التي توصلت إلى وجود فرق ذو دلالـه احصـائيه بين متوسطي دراجـات الطـلاب في التطبيقيين القبلي والبعدي في الاختبـار التحصسيلي لصـالح نطبيـق البعدي. التحقق من صحة الفرض الثاني: ينص الفرض الثاني على: لأسلوب التعلم بمساعدة المحاكاة التفاعلية أثز إيجابي في تتمية التحصيل لطالبات الصف السادس بمادة العلوم. 
للتعرف على أثز استخدام أسلوب التعلم بمساعدة المحاكاة التفاعلية أنز إيجابي في تتمية

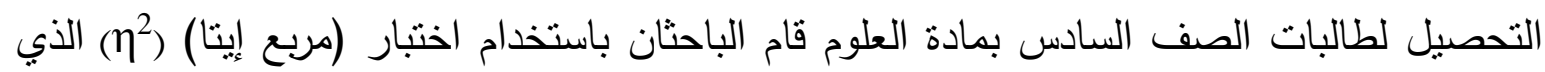
يستخدم لتحديد درجة أهمية النتيجة التي ثبت وجودها إحصائياً، وذلك وفقاً للمعادلة التالية:

مربع ايتا =

ت + ت + ت درجات الحرية

أولاً: بالنسبة لمستوى التذكر : 20

بالنطبيق من خلال بيانات الجدول المتعلق بمستوى التذكر وفقاً لمعادلة مربع إيتا السابقة،

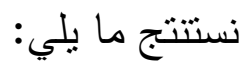

$$
\frac{\cdot, V \varepsilon=r(1 \cdot \tau, \varepsilon \cdot \cdot)}{(r \wedge)+r(1 \cdot \tau, \varepsilon \cdot \cdot)}=
$$

يتبين مما سبق أن قيمة مربع إيتا بالنسبة لبعد مستوى التذكر بلغت (ع V, · ) وهي قيمة تتجاوز القيمة الدالة على الأهمية التربوية للنتائج الإحصائية في البحوث التربوية والنفسية ومقدارها (10, •)

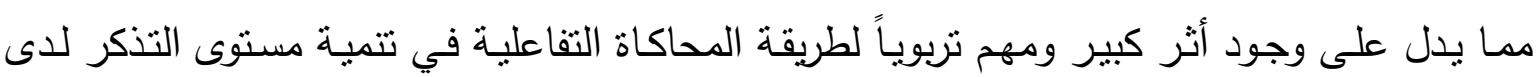
طالبات المجموعة التجريبية من الصف السادس بمادة العلوم، ومن ثم تم التحقق من صحة الفرض

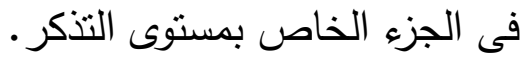
ثانياً: بالنسبة لمستوى الفهم: بالنطبيق من خلال بيانات الجدول المتعلق بمستوى الفهم وفقاً لمعادلة مربع إيتا السابقة،

$$
\text { نستتتج ما يلي: }
$$




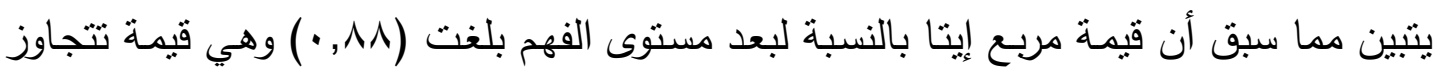
القيمة الدالة على الأهمية التزبوية للنتائج الإحصائية في البحوث التربوية والنفسية ومقدارها (10, •) مما يدل على وجود أثر كبير ومهم تربوياً لطريقة المحاكاة التفاعلية في تتميـة مستوى الفهم للى الـى طالبات المجموعة التجريبية من الصف السادس بمادة العلوم، ومن ثم تم التحقق من صحة الفرض

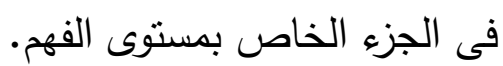
ثالثاً: بالنسبة لمستوى التطبيق: بالنطبيق من خلال بيانات الجدول المتعلق بمستوى التطبيق وفقاً لمعادلة مربع إيتا السابقة،

$$
\text { نستتتج ما يلي: }
$$

يتبين مما سبق أن قيمة مربع إيتا بالنسبة لبعد مستوى التطبيق بلغت (TVT, · ) وهي قيمة تتجاوز القيمة الدالة على الأهية التربوية للنتائج الإحصائية في البحوث التربوية والنفسية ومقدارها (10 , •)

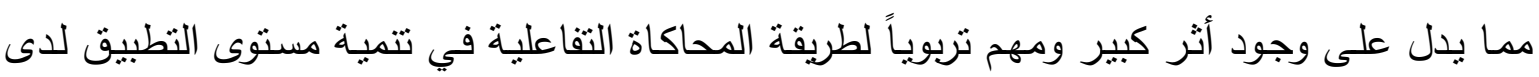
طالبات المجموعة التجريبية من الصف السادس بمادة العلوم، ومن ثم تم التحقق من صحة الفرض فى الجزء الخاص بمستوى التطبيق. رابعاً: بالنسبة لمستوى التحليل:

بالتحليل من خلال بيانات الجدول المتعلق بمستوى التحليل وفقاً لمعادلة مربع إيتا السابقة،

$$
\begin{aligned}
& \text { نستتتج ما يلي: } \\
& \cdot, 91= \\
& \text { مربع ايتا = = = } \\
& (r \wedge)+r(r \div), \cdots)
\end{aligned}
$$

يتبين مما سبق أن قيمة مربع إيتا بالنسبة لبعد مستوى التحليل بلغت (ا9,·) وهي قيمة تتجاوز القيمة الدالة على الأهمية التربوية للنتائج الإحصائية في البحوث التربوية والنفسية ومقدارها 
(10 , •) مما يدل على وجود أثز كبير ومهم نربوياً لطريقة الدحاكاة التفاعلية في تتمية مستوى التحليل للى طالبات المجموعة التجريبية من الصف السادس بمادة العلوم، ومن ثم تم التحقق من صحة الفرض فى الجزء الخاص بمستوى التحليل. خامساً: بالنسبة لمستوى التركيب: بالتركيب من خلال بيانات الجدول المتعلق بمستوى التركيب وفقاً لمعادلة مربع إيتا السابقة، نستتتج ما

$$
\text { يلي: }
$$

يتبين مما سبق أن قيمة مربع إيتا بالنسبة لبعد مستوى التركيب بلغت (؟r, ·) وهي قيمة تتجاوز القيمة الدالة على الأهمية التربوية للنتائج الإحصائية في البحوث التربوية والنفسية ومقدارها (10 , •) مما يدل على وجود أثر كبير ومهم تربوياً لطريقة المحاكاة التفاعلية في تتمية مستوى التركيب لاى طالبات المجموعة التجريبية من الصف السادس بمادة العلوم، ومن ثم نم التحقق من صحة الفرض فى الجزء الخاص بمستوى التركيب. سادساً: بالنسبة لمهارات الاختبار ككل: بالتركيب من خلال بيانات الجدول المتعلق بمهارات الاختبار ككل وفقاً لمعادلة مربع إيتا

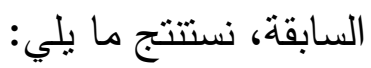

$$
\cdot, 0 \Lambda=\frac{r(01,91 \Lambda)}{(r \Lambda)+r(01,9 \Lambda \Lambda)}=
$$

يتبين مما سبق أن قيمة مربع إيتا بالنسبة لبعد مهارات الاختبار ككل بلغت (01, • ) وهي قيمة تتجاوز القيمة الدالة على الأهمية التربوية للنتائج الإحصائية في البحوث التربوية والنفسية ومقدارها (0 , •) مما يدل على وجود أثنر كبير ومهم تربوياً لطريقـة المحاكاة التفاعلية في تتميـة مهارات 
الاختبار ككل لدى طالبات المجموعة التجريبية من الصف السادس بمادة العلوم، ومن ثم تم التحقق من صحة الفرض في الجزء الخاص بمهارات الاختبار ككل. مما سبق يتبين أن المحاكاة التفاعلية المقترحة لها تأثنير إيجابي كبير في تتمية قدرة الطالبات على زيادة التحصيل وتتمية المفاهيم العلمية لديهن، وتقسر الباحثان نلك النتيجة بأن المحاكاة التفاعلية أثبتت فاعليته في الكثير من الدراسـات والأبحاث، ولها العديد من المزايـا في العملية التعليميـة بين المعلمة والطالبات، نظراً لأنه من مزايـا المحاكاة التفاعلية هو مساعدة الطالبات على تبادل الأفكار والآراء، والتي بدورها تؤدي إلى تتمية مهارات التفكير الإبداعي لديهن، كما أنها توفر التغذية الراجعة للطالبات، بما يسهم في تفعيل التعليم النشاركي بين الطالبات، وهي جميعها عوامل تساعد في تتمية قدرات الطالبات التحصيلية. كما تبين وجود أثر إيجـابي للمحاكاة التفاعليـة في تتميـة مهارات التحصبل لطالبـات الصف السادس بمادة العلوم، وتتفق هذه النتيجة مع ما توصلت إليه دراسة (كوثر) التي أثتتت فاعلية استخدام برمجيـات المحاكـاة التفاعليـة في تتميـة التحصـيل المعرفي وقدرة الطـلاب على الفهم والاسـتيعاب للموضوع الدراسي المطلوب في ماده العلوم، وكذللك اتققت مع دراسة (زارع، 1 • rم) التي توصلت إلى فاعلية البرنامج المقترح في تدريس موضوعات الجغرافيا بمقرر الدراسات الاجتماعيه لدى التناميذ.

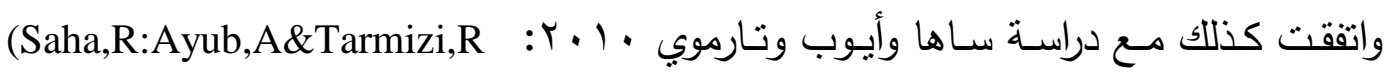
2010)() ، التي أثنـارت إلى فاعليـة برمجيـة المحاكـاة المقترحة في الارتقاء بالجوانب التاليـه لتعليم الرياضيات وهي تتميه التحصيل اللدراسي ودعم القدرات البصريه وتتمية قدرات الطلاب على دراسـة الاشكال والمساحات الهندسيه.

وكذلك اتققت مع دراسة كومار وفيدليس وروسناه وروبي (Kumar: Fedelis: Rosnah \& Ruby) 2011) التي توصلت إلى وجود أثر دال احصـائيا لاستخدام منصسه مودل في تحسين مستويات اداء طلاب المجموعه التجريبية في المقرر كما اتفقت مع دراسة (الخليفة، ـــ اهـ) التي توصلت إلى أن المدونات كانت نوعا مـا فاعله (من الناحية النّفنية والوظيفية) إذا كان الهدف منها هو نشر المـاده التعليمية للجميع والتواصل مع الطلبه من دون الاهتمام بتقييد سجلات تتابع مشاركاتهم في الماده، في المقابـل يفضـل اسـتخدام نظم إداره التعلم لضـبط عمليـه التعليم الإلكترونسي وذلك لرصــ مشـاركات 
الطـلاب في سجلات الإكترونيـة موثقه. كمـا تتفوق أنظمـة إداره التعلم على المدونات في نسـيل الخدمات الإداريه والنظاميه. منتل متابعه اداء الطلاب ومشاراكتهم واختباراتهم.

\section{ثانياً: توصيات الدراسة:}

$$
\text { فى ضوء نتائج الدراسة يوصى الباحثان بما يلي: }
$$

1-استخدام المحاكاة التفاعلية في العملية التعليمية نظراً لما ثبت من فاعليتها في تتمية المفاهيم العلمية والتحصيل لدى الطالبات.

r-توفير كافة التقنيات اللازمة والبنية الأساسية اللازمة لتنبي منظومة التعليم باستخدام المحاكاة التفاعلية ب-تنبي البرامج التنرييية اللازمة للمعلمات والتي تساهم في زيادة مهارتهم التنريسية باستخدام

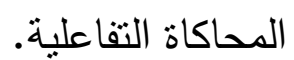
ع-تدريب المعلمات على كيفية استخدام التقنيات الحديثة في التعليم، وخاصة المحاكاة التفاعلية لما ثبت من فاعليتها في التعلم. ه-تبني استخدام المحاكاة التفاعلية من قبل معلمات العلوم كأحد الوسائل الفعالة في تدريس

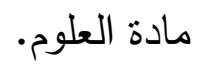

4-تحفيز الطالبات على التعلم باستخدام المحاكاة التفاعلية. V-توفير منصة تعليمية للمحاكاة التفاعلية خاصة بمادة العلوم لطلاب وطالبات المملكة العربية السعودية.

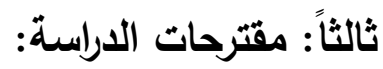

1. إجراء دراسات مقارنة عن أثز المحاكاة التفاعلية في تتمية مهارات التحصيل العلمي وبعض البرامج الأخرى لمعرفة ددى نأثير المحاكاة التفاعلية في العملية التعليمية مقارنة بالبرمجيات

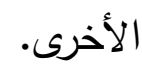
r. إجراء دراسات عن فاعلية المحاكاة التفاعلية في تتمية مهارات الطالبات في مواد دراسية أخرى. 
r. إجراء دراسات عن فاعلية المحاكاة التفاعلية في تتمية مهارات الطالبات في مراحل دراسية أخرى.

ـ. إجراء المزيد من الدراسات عن المعوقات التي تحول دون استخدام المحاكاة التفاعلية في تتمية مهارات التحصيل العلمي لاى الطالبات للوقوف على هذه المعوقات ومحاولة وضع الحلول الملائمة لها.

أبو السعود، هاني إسماعيل (9 . . r م)، برنامج تقني قائم على أسلوب المحاكاة لتتمية بعض مهارات ما وراء المعرفة منهاج العلوم لدى طلبة الصف التاسع الأساسي بغزة، رسالة ماجستير، كلية التربية، الجامعة الإسلامية غزة. أبو السعود، هاني. (9 . . rم) • برنامج تقني قائم على أسلوب المحاكاة لتتمية بعض مهارات ما وراء المعرفة في منهاج العلوم لاى طلبة الصف التاسع الأساسي بغزة. رسالة ماجستير غير منشورة، كلية التربية بالجامعة الإسلامية، غزة. أبو ماضي، ساجدة كامل (11 (1) ) : أثز استخدام الدحاكاة الحاسوبية على اكتساب المفاهيم والمهارات الكهربية بالتكنولوجيا لاى طلبة الصف التاسع الأساسي بغزة، رسالة ماجستير ، كلية التربية، الجامعة الأسلامية، غزة، فلسطين. إسماعيل، الغريب زاهر ( ( . ب). تكنولوجيا المعلومات وتحديث التعليم، المنصورة، دار الوفاء.

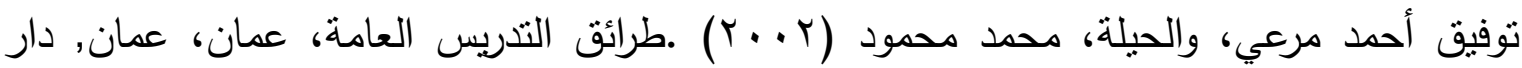
المسيرة للنشر والتوزيع والطباعة.

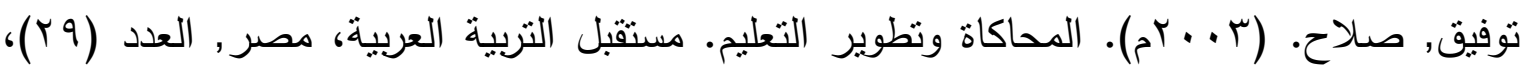

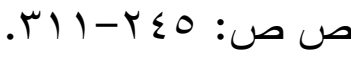
جابر ، جابر عبد الحميد. (0. بץ). التدريس والتعلم - الأسس النظرية - الاستراتيجيات والفاعلية،

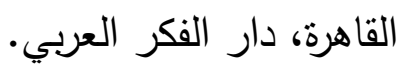
جابر ، محمد. (· • • ( ) • برامج المحاكاة، منوفر على الرابط: 
Http://Kenanaonline.Com/Users/Azharaper/Topics/70551/Posts/155254 .

الجريوي, عبدالمجيد عبدالعزيز • (• • r م) • تقويم تجربة الجامعات السعودية في استخدام نظام إدارة التعليم الإلكتروني (جسور ) • رسالة دكتوراه غير منشورة. كلية التربيه, جامعة ام القرى، مكة المكرمة. حنا، رمزي كامل وجرجس، ميشيل تكلا (1991 م). معجم المصطلحات التربوية، بيروت: مكتبة لبنان. الحيلة, محمد محمود (ع + . rم) ـ تكنلوجيا التعليم بين النظرية والتطبيق. طع دار المسيرة للنشر والتوزيع والطباعة.عمان. خان، بدر • (0 . † ) ـ استيراتيجيات التعلم الإلكتروني. حلب: شعاع للنشر والعلوم. الخليفة, هند (•rع ( ) من المدونات إلى نظام التعليم جسور ، المؤتمر الدولي الأول للتعلم الإكتروني

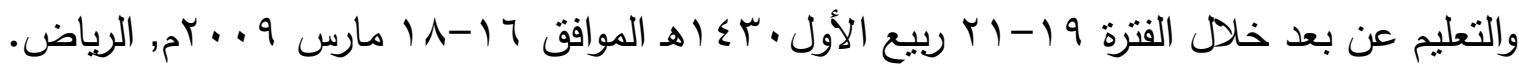

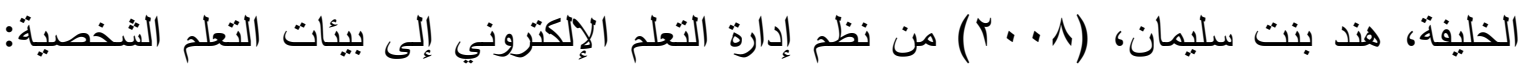

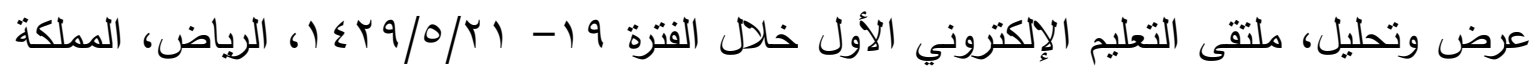

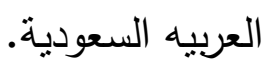

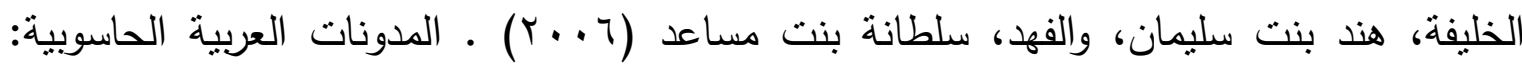
دراسة تحليلة،الندوة الوطنية الأولى لتقنية المعلومات، الرياض.

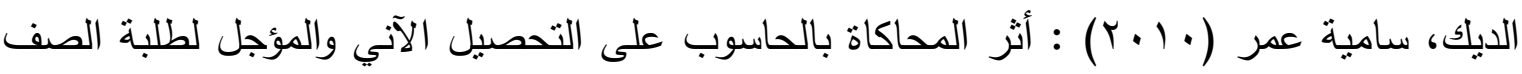
الحادي عشر العلمي واتجاهاتهم نحو وحدة الميكانيكا ومعلمها، رسالة ماجستير، كلية التربية، جامعة النجاح الوطنية، نابلس.

الديك، سامية عمر فارس. (• ( ب). أثر المحاكاة بالحاسوب على التحصيل الآني والمؤجل لطلبة الصف الحادي عثر العلمي واتجاهاتهم نحو وحدة الميكانيكا ومعلمها. رسالة ماجستير، جامعة النجاح الوطنية في نابلس.

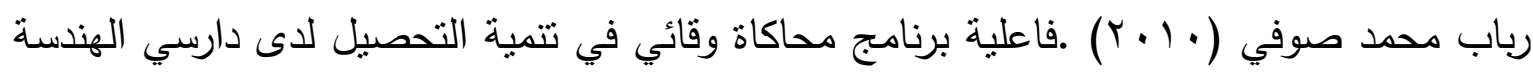
الوراثية،رسالة ماجستير ،معهد الدراسات والبحوث التربوية،جامعة القاهرة. 
زارع، أحمد زارع احمد. (· ( ب). فاعلية برنامج مقترح قائم على المحاكاة الإكترونية لتدريس الدراسات الاجتماعيه في تتمية التحصبل والقدرة المكانية والاتجاه نحو المادة لدى تلاميذ المرحلة

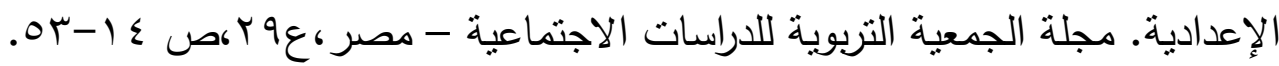
زيتون، كمال عبدالحميد (ع . . ץ) ـ تكنولوجيا التعليم في عصر المعلومات والاتصالات، ط (Y) ,

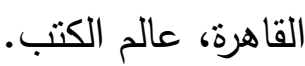
صبري، ماهر وتوفيق، صلاح الدين (0.r) : التوير التكنولوجي وتحديث التعليم، المكتب الجامعي الحديث، الإسكندرية، جمهورية مصر العربية. عاشور، محمد إسماعيل (9 . . r) . فاعلية برنامج Moodle في اكتساب مهارات التصميم ثلاثي الأبعاد لاى طلبة تكنلوجيا التعليم الجامعة الأسلامية. رسالة ماجستير غير منشورة، كلية التربية، الجامعة الإسلامية بغزة، دولة فلسطين. عبدالمجيد، أحمد. (· ( • ( ) • برنامج مقترح في التعليم الإكتروني باستخدام البرمجيات الحرة مفتوحة المصدر وأثره في تتمية مهارات تصميم وإنتاج دروس الرياضيات الإلكترونية لدى الطلاب المعلمين. كلية التربية بسوها ج,مصر ·

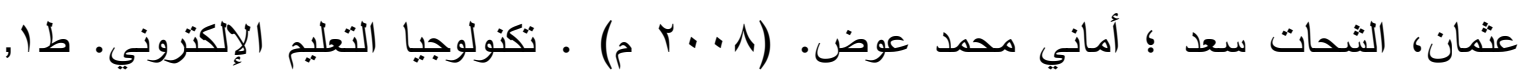
مصر ، دمباط: مكتبة نانسي. العمودي, سعيد. (0 . ץ) ـ أنظمة إدارة المقررات في مؤسسات التعليم العالي، في: التعليم عن بعد بين النظرية والتطبيق. الكوبت:أمانة لجنة مسئولي التعليم عن بعد بجامعات ومؤسسات التعليم العالي لدول الخليج العربي.

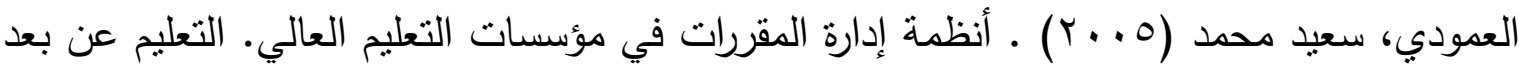
بين النظرية والتطبيق.جامعة الكويت: أمانة لجنة مسئولي التعليم عن بعد بجامعات ومؤسسات التعليم العالي لدول الخليج العربي.

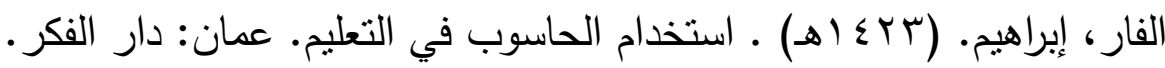

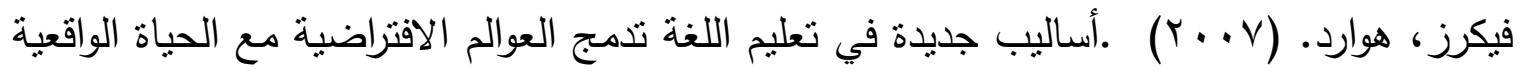
منوفرة (مقالة مترجمة) على الإنترنت منوفر على الرابط: http://www.saidaonline.com/news.php?go=fullnews\&newsid=178 


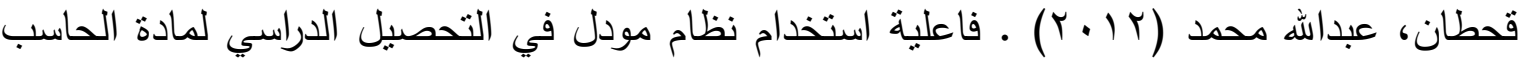
الآلي ومهارات التواصل الإلكتروني لطلاب المرحلة الثانوية. رسالة ماجستير ، جامعة الباحه. قنديل،يس عبدالرحمن (999 (م) ـالوسائل التعليمية وتقنيات التعليم (المضمون -العلاقة ـالتصنيف) (المجلد طץ). الرياض: دار النشر الدولي. محمد, نبيل السيد. (· • (rم). فاعلية مقرر إلكتروني لتتمية مهارات استخدام نظام موودل لدى طلاب الدراسيات العليا وأثره على التحصيل المعرفي والدافعية للانجاز ـ كلية التربيه،

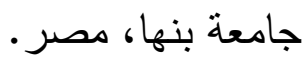
(Zspace) http://zspace.com/corporate-training ثانياً: المراجع الأجنبية:

Allens, W، (2006) .Creating successful e-learning: a rapid system for creating it right first time, every time. Chicago: Rand-McNally.

Bell, R.and Trundle, K. (2008) .The use of a computer simulation to promote scientific conception of moon phases. Journal of Research in Science Teaching، 45 (3), 346-372.

Ellis, Ryann K. (2009) Field Guide to Learning Management Systems, ASTD Learning Circuits.

Karl M. Kapp. (2007). Defining and Understanding Virtual Worlds. Available online http://www.learningcircuits.org/2007/0507kapp.ht

Livingstone, Daniel, Ed.; Kemp, Jeremy, Ed. (2006). Putting a second life "metaverse" skin on learning management systems. Proceedings of the Second Life Education

Mcadam، R.J. (2010). Continuous interactive simulation: Engaging the human sensorymotor system in understanding dynamical systems.Procedia-Computer Science، 1، 16911698.

Nicole, S. \& Tracey H. (2003), Virtual Reality/Computer Simulations, National Center On Accessing The General Curriculum (NCAC) Pdf.

Primoz, L. \& Tomaz, P. (2007), practical e-learning for the faculty of mathematics and physics at the University of Ljubljana.Journal of knowledge and Learning Objects. 3 (1), PP 12-23.

Rankine, Lynnae et al (2009). Benchmarking across universities: A framework for LMS analysis, In Same places, different spaces, proceedings ascilite, Auckland. 
Saha, R: Ayub, A \& Tarmizi, R. (2010). The effects of GeoGebra on mathematics achievement: Enlightening coordinate geometry Iearning. Procedia-Social and Behavioral Sciences, 8, pp 686-693.

Tomas, E. \& Pedro, M. (2012). The Acceptance of Moodle Technology by Business Administration Students. Computers \& Education, 58 (4), pp 1085-1093.

Workshop, Part of the Second Life Community Convention (1st, San Francisco, California, August 18-20, 2006).

Yusuf, M. \& Afolabi, A. (2010). Effects of computer assisted instruction (CAI) on secondary school students' performance in biology، The Turkish Online Journal of Educational Technology, 9 (1):p62-69. 